\title{
Paleoceanography
}

\section{RESEARCH ARTICLE \\ 10.1002/2016PA002951 \\ Accounting for centennial-scale variability when detecting changes in ENSO: A study of the Pliocene}

Key Points:

- Substantial centennial-scale

variability in the strength of Pliocene and preindustrial ENSO

- Compared to preindustrial, Pliocene El Niño was stronger, less frequent, and shifted to the west

- Intrinsic, low-frequency ENSO variability important when determining ENSO changes between climates

Supporting Information:

- Supporting Information S1

- Figure S1

- Figure S2

- Figure S3

- Data Set S1

- Data Set S2

- Data Set S3

- Data Set S4

- Data Set S5

- Data Set S6

Correspondence to:

J. C. Tindall,

J.C.Tindall@leeds.ac.uk

Citation:

Tindall, J. C., A. M. Haywood, and F. W. Howell (2016), Accounting for centennial-scale variability when detecting changes in ENSO: A study of the Pliocene, Paleoceanography, 31, 1330-1349, doi:10.1002/2016PA002951.

\section{Received 11 MAR 2016}

Accepted 6 SEP 2016

Accepted article online 21 SEP 2016 Published online 11 OCT 2016

๑2016. American Geophysical Union. All Rights Reserved.

\author{
Julia C. Tindall ${ }^{1}$, Alan M. Haywood ${ }^{1}$, and Fergus W. Howell ${ }^{1}$ \\ ${ }^{1}$ School of Earth and Environment, University of Leeds, Leeds, UK
}

\section{Introduction}

The El Niño-Southern Oscillation (ENSO) is the dominant mode of interannual climate variability. Although predominantly a tropical Pacific phenomenon, its teleconnections extend across the globe [McPhaden et al., 2006; Alexander et al., 2002; Hoerling et al., 1997; L'Heureux and Thompson, 2006; Cai et al., 2011]. Its influence on weather can be severe, with strong El Niño events associated with natural disasters such as droughts, floods, and tropical cyclones [e.g., Philander, 1983; The Economist, 1998]. It affects agriculture [Cane et al., 1994] and freshwater supplies [Meehl, 1996] and can also impact ecosystems (for example, Glynn and Deweerdt [1991] suggested that the 1982-1983 El Niño event contributed to the demise of a coral species).

Due to the important societal impacts of ENSO, a great deal of research has focused on understanding this phenomenon in the present and how it will change in the future [e.g., McPhaden et al., 2006; Yeh et al., 2009; Power et al., 2013]. However, ENSO exhibits substantial variability at interdecadal-centennial timescales [Wittenberg, 2009; Li et al., 2011], meaning that instrumental records, available for only the last 150 years, are too short to capture the full range of this variability and thus ascertain whether ENSO is changing as climate warms.

Long records of paleo-ENSO variance from tree rings [ $L i$ et al., 2013] or multiple proxy reconstructions [McGregor et al., 2013] suggest that the late twentieth century ENSO activity was anomalously high in the context of recent centuries. However, evidence from fossil corals [Cobb et al., 2013] suggests that the high twentieth century ENSO variance is not unprecedented. Model results from phase 3 of the Coupled Model Intercomparison Project (CMIP3) show no consensus as to whether ENSO variability will increase in the future [Collins et al., 2010]. However, they do show an increase in extreme El Niño events [Cai et al., 2014], such as that of 1982/1983, one of the strongest since records began, and that of 1997/1998, which has been referred to as "the climate event of the century" [Changnon, 2000]. 
In addition to determining whether ENSO variability is changing, it is also important to assess whether the structure of El Niño is changing. There has recently been much discussion about a new flavor of El Niño, which has been termed El Niño Modoki [Ashok et al., 2007], the dateline El Niño [Larkin and Harrison, 2005], the central Pacific El Niño [Kao and Yu, 2009], and the warm pool El Niño [Kug et al., 2009]. This new flavor of El Niño (hereafter referred to as El Niño Modoki) is characterized by a maximum warming in the equatorial central Pacific, flanked by colder sea surface temperatures to the east and west. Observations show that the standard (canonical) El Niño has been less frequent in the late twentieth century while the occurrence of El Niño Modoki has been increasing [An and Wang, 2000; Ashok et al., 2007; Kao and Yu, 2009]. CMIP3 model simulations of the SRESA1B climate change scenario suggest that the ratio of Modoki to canonical El Niño will increase further as climate warms [Yeh et al., 2009]. The different "flavors" of El Niño have different teleconnections [Ashok et al., 2007; Yeh et al., 2009] and different societal impacts; hence, understanding changes in El Niño structure is important for predicting climate impacts.

To understand the changing nature of El Niño in a warmer world, it can be useful to look at El Niño in warm climate periods of the past. One period which has attracted a great deal of attention is the mid-Pliocene Warm Period (mPWP), which occurred 3.3 to 3.0 Ma. This period represents a warm and stable climate, where global annual mean sea surface temperatures were $2-3^{\circ} \mathrm{C}$ higher than preindustrial [Dowsett et al., 2010; Haywood et al., 2000] and polar ice sheets were reduced by up to one third relative to today [Dolan et al., 2011]. There is large uncertainty of greenhouse gas levels for this time, but best estimates suggest that up to 400 ppmv was reasonable [Seki et al., 2010]. Although this is not analogous to the transient and constantly increasing greenhouse gas levels we see today, it is an ideal time period for studying the likely response of El Niño to a warm equilibrium climate state and is relevant to today since it is recent enough that the continental configuration is close to modern.

There have been many studies suggesting that the Pliocene tropical Pacific was in a state of permanent El Niño. Some of these have been based on bulk measurements in the Pacific Ocean [e.g., Philander and Fedorov, 2003; Wara et al., 2005; Seki et al., 2012], which are not of sufficiently high resolution to determine whether there was ENSO-related variability superimposed on this permanent El Niño-like state. Other studies have suggested a permanent Pliocene El Niño based on climate patterns that occur today due to El Niño teleconnections [e.g., Molnar and Cane, 2002; Winnick et al., 2013]. However, Bonham et al. [2009] noted the possibility of equifinality, where some of these climate patterns could have existed in the Pliocene for an alternative reason, and do not necessitate a permanent El Niño.

Modeling studies of the mPWP suggest ENSO variability in the Pliocene and do not show a permanent El Niño state [Haywood et al., 2007; Bonham et al., 2009; von der Heydt et al., 2011; Brierley, 2015]. ENSO variability in the Pliocene has also been found in a number of data sets [Watanabe et al., 2011; Scroxton et al., 2011; Zhang et al., 2014], suggesting that regardless of the mean state of the tropical Pacific in the Pliocene, there was likely ENSO variability at this time.

Although ENSO-related variability can be detected in data, most data of Pliocene age are not of sufficient temporal and spatial resolution to suggest whether the structure, amplitude, or frequency of ENSO has changed. However, high-resolution coral data [Watanabe et al., 2011] suggest similar ENSO variability to today. More detailed information about how ENSO in the Pliocene may have differed from today has been provided by models. The most comprehensive study of the strength of Pliocene El Niño is that of Brierley [2015] which looked at the nine models that made up the Pliocene Model Intercomparison Project (PlioMIP) ensemble [Haywood et al., 2013]. He found that eight of the nine models showed reduced ENSO-related variability in the Pliocene. This robustly weaker ENSO was also associated with a shift to lower frequencies. He noted that the PlioMIP models were unexpectedly consistent in their representation of ENSO, and the likelihood of this result occurring by chance was slim. However, one of the PlioMIP models, HadCM3, which Brierley [2015] found to be weaker in the Pliocene, was actually found to be stronger when results from an alternative simulation were considered [Scroxton et al., 2011]. This suggests that there could be some intramodel variability of Pliocene El Niño and that this must be considered before robust conclusions can be drawn.

This paper will complement the study of Brierley [2015] by looking at intramodel ENSO variability within a multimillennial-scale simulation of a single model (HadCM3). This is needed because the majority of the PlioMIP simulations have been run for at most 500 years and cannot fully capture the substantial variability at interdecadal-centennial timescales which exist for modern ENSO. This paper will also focus on different ways of detecting Pliocene El Niño in order to assess what the most robust changes are between the Pliocene and 
the preindustrial. In section 2 we will describe the model and the experiments used in this paper. Section 3 will show how ENSO variability in the NINO3.4 region varies over a long simulation and will also discuss how small differences in the boundary conditions of a simulation will affect ENSO. Section 4 will consider ENSO teleconnections, ENSO in the NINO4 regions, and will relate El Niño climate patterns to El Niño Modoki and the Pacific Decadal Oscillation. Conclusions are presented in section 5.

\section{Methods}

\subsection{Model Description}

This study uses results from the Hadley Centre General Circulation Model (HadCM3) [Gordon et al., 2000; Pope et al., 2000], a general circulation model that has been used in many scientific studies including the Intergovernmental Panel on Climate Change Fourth and Fifth Assessment Reports [Solomon et al., 2007; Stocker et al., 2013]. Its resolution is $3.75^{\circ} \times 2.5^{\circ}$ with 19 vertical levels in the atmosphere and $1.25^{\circ} \times 1.25^{\circ}$ with 20 vertical levels in the ocean. It uses the Gregory and Rowntree [1990] convection scheme, a large-scale cloud scheme based on Smith [1990] with modifications described by Gregory and Morris [1996], and the Edwards and Slingo [1996] radiation scheme. In the ocean HadCM3 comprises a simple sea ice model, which is based on the zero-layer model of Semtner [1976] (and includes ice drifts, leads, and snow cover).

The experiment runs using HadCM3 will make use of two versions of the Met Office Surface Exchange Scheme (MOSES1 and MOSES2), which calculate exchanges of heat, moisture, momentum, and $\mathrm{CO}_{2}$ between the surface and the atmosphere. The main difference between the two schemes is how surface fluxes from the land are calculated at a gridbox scale. MOSES2 [Essery et al., 2001] uses a tiled model of subgrid heterogeneity such that fluxes are computed separately for each of the nine surface types (broadleaf trees, needleleaf trees, temperate grass, tropical grass, shrubs, urban, inland water, bare soil, and ice). MOSES1 [Cox et al., 1999] does not explicitly represent surface types and instead uses effective parameters to perform a single set of surface flux calculations for each gridbox. MOSES2 includes different surface types and is here run with the TRIFFID dynamic vegetation model [Cox, 2001], such that vegetation will fully interact with the climate and will change throughout a long simulation.

HadCM3 has been used in a number of studies of the MPWP and in particular has been run as part of PlioMIP [Bragg et al., 2012; Haywood et al., 2013]. It is generally in good agreement with reconstructions although it does underpredict the Pliocene sea surface temperature (SST) warming over the North Atlantic region [Prescott et al., 2014] and the Northern Hemisphere high-latitude terrestrial warming [Salzmann et al., 2013].

HadCM3 provides a reasonable representation of present-day ENSO, including an amplitude and frequency broadly in agreement with observations [Bellenger et al., 2014]. Its skill at simulating ENSO compares well with other CMIP3 and CMIP5 models [see Bellenger et al., 2014, Figure 13], and its occurrence ratio of El Niño Modoki/El Niño canonical for the modern climate is close to observations [Yeh et al., 2009, supplementary information]. However, HadCM3 shows a stronger shift toward El Niño Modoki under a warming scenario than other models [Yeh et al., 2009].

The HadCM3 model has been used to simulate ENSO in the Pliocene [Scroxton et al., 2011; Bonham et al., 2009; Haywood et al., 2007]. HadCM3 shows that the mPWP includes ENSO-related variability with a more periodic, regular-amplitude ENSO fluctuation than preindustrial.

\subsection{Experimental Design}

To analyze the range of Pliocene ENSO behavior in HadCM3, we will utilize data from a number of experiments (summarized in Table 1). All Pliocene experiments use boundary conditions from the Pliocene Research, Interpretation and Synoptic Mapping project (PRISM) [Dowsett et al., 1994], with ice sheets, orography, and initial vegetation parameters from the PRISM3D version [Dowsett et al., 2010], which was used for PlioMIP. All experiments also use the "alternative" experimental design for PlioMIP, meaning that the continental configuration is as preindustrial.

The first set of experiments in Table 1 is that run by Bragg et al. [2012] as part of PlioMIP and has previously been analyzed for ENSO variability by Brierley [2015]. The preindustrial and Pliocene experiments from this set, hereafter referred to as Preind ${ }_{B r a g g}$ and Plio $_{B r a g g}$, have fixed vegetation parameters based on the MOSES1 land surface scheme [Cox et al., 1999] and modern orbit. The Plio $_{\text {Bragg }}$ experiment was initialized from the end of a Pliocene experiment [Lunt et al., 2012] which had run for 1000 years and included boundary conditions from an earlier version of PRISM (PRISM2). Since one of the aims of this paper is to consider centennial-scale 
Table 1. HadCM3 Simulations Used in This Study

\begin{tabular}{lccccc}
$\begin{array}{l}\text { Experiment } \\
\text { Name }\end{array}$ & Period & $\begin{array}{c}\text { Run } \\
\text { Length }\end{array}$ & Orbit & $\begin{array}{c}\text { Vegetation } \\
\text { Scheme }\end{array}$ & Notes \\
\hline Plio $_{\text {Bragg }}$ & Pliocene & 500 & modern & MOSES1 & \\
Preind $_{\text {Bragg }}$ & Preindustrial & 200 & modern & MOSES1 & \\
Plio $_{\text {Bragg-add }}$ & Pliocene & 500 & modern & MOSES1 & continued from Plio \\
Breind $_{\text {Bragg-add }}$ & Preindustrial & 500 & modern & MOSES1 & continued from Preind \\
Bragg $_{2500}$ & Pliocene & 2500 & $3.205 \mathrm{Ma}$ & MOSES2 & \\
Preind $_{2500}$ & Preindustrial & 2500 & modern & MOSES2 & \\
Plio $_{\text {orb-3185 }}$ & Pliocene & 500 & $3.185 \mathrm{Ma}$ & MOSES2 & started \\
Plio $_{\text {orb-3195 }}$ & Pliocene & 1500 & $3.195 \mathrm{Ma}$ & MOSES2 & from \\
Plio $_{\text {orb-3215 }}$ & Pliocene & 1500 & $3.215 \mathrm{Ma}$ & MOSES2 & Plio $_{2500}$ \\
Plio $_{\text {orb-3225 }}$ & Pliocene & 1500 & $3.215 \mathrm{Ma}$ & MOSES2 & (year 1200) \\
\hline
\end{tabular}

variability in ENSO, we have extended the standard PlioMIP experiments, Plio $_{\mathrm{Bragg}}$ and Preind $\mathrm{Bragg}$, to provide an extra 500 years of model output. This extension comprises two additional simulations, Plio $_{\text {Bragg-add }}$ and Preind ${ }_{\text {Bragg-add }}$, which are direct continuations of Plio $_{\text {Bragg }}$ and Preind $d_{\text {Bragg }}$.

The longest experiment to be analyzed in this paper has been run for 2500 years for the Pliocene; it will hereafter be referred to as $\mathrm{Plio}_{2500}$ and is paired with a 2500 year preindustrial experiment, Preind ${ }_{2500}$. Both $\mathrm{Plio}_{2500}$ and Preind $\mathrm{d}_{2500}$ were started from the end of a standard preindustrial experiment which had already run for several millennia; however, $\mathrm{PliO}_{2500}$ was first adapted to PRISM3D boundary conditions through changing the vegetation, ice sheets, and orography. Orbital parameters were set to $3.205 \mathrm{Ma}$, which is very close to modern, and $\mathrm{CO}_{2}$ levels to $405 \mathrm{ppm}$. Although this experiment had initial vegetation parameters from PRISM3D, this simulation uses the MOSES2 land surface exchange scheme, including the TRIFFID dynamic vegetation model, so that Pliocene vegetation is simulated rather than prescribed. The main differences between Plio $_{B_{\text {Bragg }}}$ and $\mathrm{PliO}_{2500}$ are therefore initial conditions, simulation length, orbit (3.205 Ma for $\mathrm{PliO}_{2500}$ and modern for $\mathrm{Plio}_{\mathrm{Bragg}}$ ), and vegetation (dynamic for $\mathrm{Plio}_{2500}$ and static for Plio $_{\text {Bragg }}$ ).

Since one of the differences between $\mathrm{PliO}_{2500}$ and $\mathrm{Plio}_{\mathrm{Bragg}}$ was the use of a different orbit, some further experiments will be analyzed in order to assess the sensitivity of Pliocene El Niño to subtle changes in orbit. The orbits chosen were 3.185 Ma, 3.195 Ma, 3.215 Ma, and 3.225 Ma, most of which were discussed by Haywood et al. [2013]. The Pliocene experiments with alternative orbits were initialized from the middle of $\mathrm{Plio}_{2500}$ and were run for up to 1500 years.

For practical purposes, these experiments will be subdivided into 200 year timeslabs so that variability within a simulation can be analyzed to determine the full range of ENSO behavior. The 200 years was chosen for the timeslab length because this is the length of the shortest simulation to be analyzed (Preind $\mathrm{Bragg}$ ) and also allows the longest (2500 year) simulation to be divided into 12 timeslabs which provides a range of values for comparison. However, the choice of using 200 year timeslabs is somewhat arbitrary and a brief discussion of the sensitivity of results to timeslab length will be included. Each 200 year timeslab will be allocated a number dependent on how long into the simulation it is (e.g., years 0-200 of the simulation being denoted timeslab 1 and years $200-400$ of the simulation denoted timeslab 2). If necessary timeslabs will be allocated noninteger numbers, for example, years 300-500 would be allocated to timeslab 2.5 .

\section{Variability in Pliocene El Niño}

Many climate modeling studies investigate climate behavior by looking at the final decades or centuries of a simulation, so that the model is most likely to represent a fully spun-up state. We therefore first consider the strength of ENSO in the final 200 years of the $\mathrm{Plio}_{2500}$ simulation and the Preind ${ }_{2500}$ simulation. This was determined from the standard deviation of SST anomalies [Guilyardi et al., 2009; Bellenger et al., 2014; Brierley, 2015] after removing the annual cycle and other high-frequency variability by smoothing the data with a Lanczos low-pass filter of 18 months. This initial analysis shows that the standard deviation in the NINO3.4 region is $0.63^{\circ} \mathrm{C}$ for the Pliocene simulation and $0.52^{\circ} \mathrm{C}$ for the preindustrial simulation. The ratio of Pliocene to preindustrial variance gives an $F$ statistic of 1.47 , which, for a sample size of 2400 months, shows a significant 
change in variance between the two populations at the $0.1 \%$ confidence level. This shows that in the final 200 years of the simulation ENSO variability was stronger in the Pliocene and that this increased variance is statistically significant.

This result does not appear consistent with the study of Brierley [2015]. He found that HadCM3 (experiment $\mathrm{Plio}_{\text {Bragg }}$ ) showed lower standard deviation in the NINO3.4 region for the Pliocene, in agreement with the majority of the PlioMIP ensemble. To ensure consistency of method, we have also analyzed the data from $\mathrm{Plio}_{\text {Bragg }}$ and find identical results to that of Brierley [2015].

Although looking at NINO3.4 standard deviation highlights an important difference between the similar HadCM3 experiments, $\mathrm{Plio}_{\mathrm{Bragg}}$ and $\mathrm{PliO}_{2500}$, that must be explained, the difference does not follow through to other indicators of El Niño. For example, both $\mathrm{PliO}_{2500}$ and $\mathrm{Plio}_{\text {Bragg }}$ show fewer El Niño events than their preindustrial equivalent and approximately the same number of La Niña events as their preindustrial equivalent. When an El Niño does occur in $\mathrm{PliO}_{2500}$ and Preind ${ }_{2500}$, the average amplitude in the NINO3.4 region is approximately $18 \%$ greater in the Pliocene simulation (discussed in section 4). Although not entirely consistent with the Bragg et al. [2012] simulations, partitioning Plio $_{\text {Bragg }}$ into 200 year chunks (from years 100-300 and years $300-500$ ) is inconclusive since the first Pliocene chunk suggested a $2 \%$ weaker El Niño in the Pliocene, while the second suggested a $9 \%$ stronger El Niño. This suggests that there is some century-scale variability in modeled El Niño, which must be accounted for if any definitive conclusions are to be drawn.

\subsection{Sensitivity Tests to Investigate Intramodel Differences in EI Niño}

Before centennial-scale variability is discussed, it is important to consider whether there are any differences in model setup that could potentially lead to contrasting results from the same model. Although the model setup for $\mathrm{Plio}_{2500}$ and $\mathrm{Plio}_{\text {Bragg }}$ are not identical, the differences in model setup do not initially appear significant enough to explain a dramatic change in model behavior. The differences are as follows:

1. $\mathrm{Plio}_{2500}$ used the orbit of the PRISM4 timeslice at 3.205 Ma [Haywood et al., 2013], which is close to, but not identical to, the modern orbit used by Plio $_{\text {Bragg }}$. The sensitivity of ENSO to changes in orbit will be discussed in section 3.2 .

2. Plio $_{2500}$ and Preind ${ }_{2500}$ use the MOSES2 land surface scheme and the TRIFFID dynamic vegetation scheme [Cox, 2001], such that vegetation is predicted by the model rather than being prescribed, while Plio $_{\text {Bragg }}$ and Preind $d_{\text {Bragg }}$ use the MOSES1 vegetation scheme and fixed vegetation parameters obtained from the Salzmann et al. [2008] data set. The effect of the vegetation scheme on ENSO is further discussed in section 3.3.

3. The simulations have been run for different lengths of time. $\mathrm{Plio}_{2500}$ has been run with consistent PRISM3D boundary conditions for 2500 years, while Plio $_{\text {Bragg }}$ was started from the end of a PRISM2 simulation and run with PRISM3 boundary conditions for 500 years. The effects of spin-up and run length on ENSO behavior are discussed in section 3.4 .

In order to assess the model sensitivities and variability, the standard deviation in the NINO3.4 region from all the experiments is shown in Figure 1. Each simulation has been subdivided into 200 year timeslabs in order to investigate internal model variability of ENSO behavior within the same simulation; each timeslab is shown separately on the figure. In Figure 1, red symbols represent results from Pliocene experiments, while blue symbols represent results from preindustrial experiments. Triangles show results from the Bragg et al. [2012] experiments (including the additional experiments run by us), while stars show results based on the dynamic vegetation 2500 year experiment. The apparently contradictory results between the final 200 years of the simulation to be analyzed in this paper and those analyzed by the Brierley [2015] paper are shown by the red and blue stars on timeslab 12 and the blue and red triangles on timeslab 1, respectively. However, this apparent contradiction fades when all the other timeslabs are considered. A $t$ test to determine whether the mean value of the NINO3.4 standard deviation differs between the Pliocene and the preindustrial gives a $p$ value of 0.44 , meaning that we are less than $60 \%$ confident that the HadCM3 mean NINO3.4 standard deviation differs between the Pliocene and the preindustrial. To assess the sensitivity of this analysis to the length of the timeslabs, supporting information Figure $\mathrm{S} 1$ is analogous to Figure 1, but each experiment has been subdivided into 100 year timeslabs. Both Figures 1 and S1 show large differences between timeslabs for both the preindustrial and the Pliocene and substantial overlap between the two time periods. However, as expected, the differences between timeslabs are amplified for the shorter (100 year timeslab) case. 


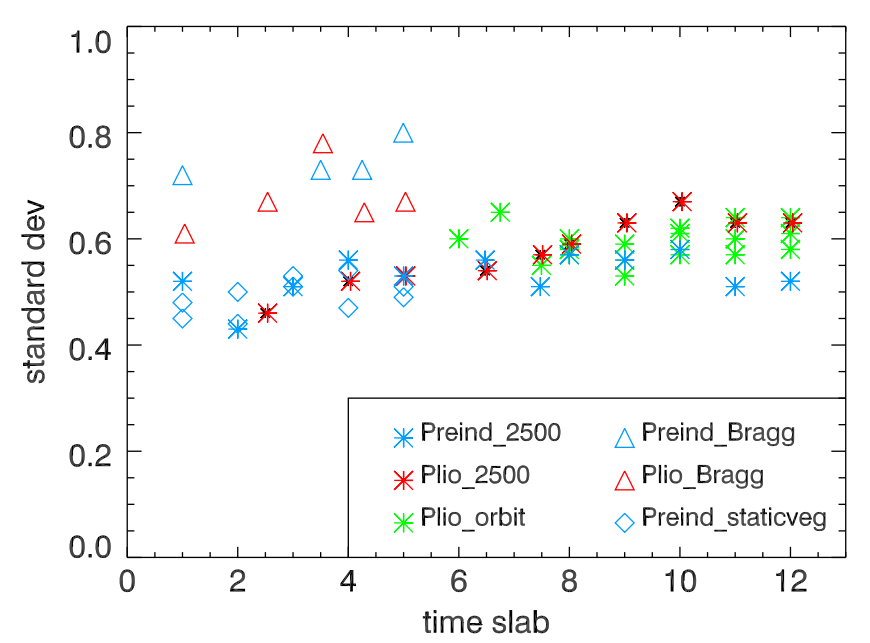

Figure 1. Standard deviation in the NINO3.4 region (after smoothing with a Lanczos low-pass filter of 18 months) from all simulations. Triangles are MOSES1 simulations based on Bragg et al. [2012], stars are MOSES2-TRIFFID simulations with dynamic vegetation based on the 2500 year simulations, and diamonds show MOSES2 simulations with static vegetation. Different colors represent different periods as shown in the key. Each time slab represents a consecutive 200 year subset of each simulation. The green stars show the range of MOSES2-TRIFFID simulations with orbits ranging from $3.185 \mathrm{Ma}$ to $3.225 \mathrm{Ma}$.

\subsection{Orbital Effects}

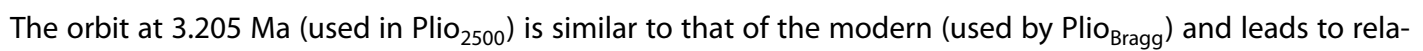
tively minor changes in climate. Haywood et al. [2013] showed that the difference in climate between using the 3.205 Ma orbit and the preindustrial orbit was less than the difference between using the $3.205 \mathrm{Ma}$ orbit and an orbit representing $3.195 \mathrm{Ma}$. Therefore, in order to consider whether changes in orbit could possibly lead to the differences in ENSO behavior, sensitivity tests considering alternative orbits within 20,000 years of 3.205 Ma are considered. These orbits represent 3.185 Ma, 3.195 Ma, 3.215 Ma, and 3.225 Ma; the mean absolute differences averaged over all months and latitudes, in the incoming shortwave radiation flux (sw) between these orbits and $3.205 \mathrm{Ma}\left(\frac{1}{(n \times m)} \sum_{i=1}^{n} \sum_{j=1}^{m}\left|\mathrm{sw}_{\mathrm{orb}}(i, j)-\mathrm{sw}_{3.205}(i, j)\right| ; n=\right.$ no. of latitudes, $m=$ no. of months), are $10.5 \mathrm{~W} / \mathrm{m}^{2}, 13.8 \mathrm{~W} / \mathrm{m}^{2}, 3.3 \mathrm{~W} / \mathrm{m}^{2}$, and $9.9 \mathrm{~W} / \mathrm{m}^{2}$, respectively (see also figures in Prescott et al. [2014]). Some of these orbits have mean absolute difference from 3.205 Ma that is larger than the mean absolute difference in the incoming shortwave radiation flux between $3.205 \mathrm{Ma}$ and the modern $\left(5.6 \mathrm{~W} / \mathrm{m}^{2}\right)$. The experiments with alternative orbits were started from the middle of the standard 3.205 Ma Pliocene experiment at timeslab 6 and are shown by the green stars in Figure 1.

Although some of these different orbits represent a relatively larger change to our simulation than using the modern orbit, Figure 1 clearly shows that the majority of experiments with alternative orbits agree with the 3.205 Ma, $\mathrm{Plio}_{2500}$ experiment in that the Pliocene NINO3.4 standard deviation is greater than that of the preindustrial. There are occasions where an alternative orbit leads to Pliocene NINO3.4 standard deviation being reduced relative to the preindustrial (see, for example, one of the orbits on timeslab 9); however, there are also occasions where the standard $\mathrm{PliO}_{2500}$ NINO3.4 standard deviation is lower than the preindustrial (see stars on timeslab 4 and timeslab 6). All orbits give results which are within the range of the standard 3.205 Ma Pliocene experiment, and therefore, differences in orbit do not appear to cause significant changes in this metric of ENSO variability. This also suggests that ENSO strength was reasonably robust throughout the period 3.185 Ma-3.225 Ma, despite climate differences [Prescott et al., 2014].

\subsection{Land Surface Effects}

The most notable difference between the setup of $\mathrm{Plio}_{\text {Bragg }}$ and $\mathrm{Plio}_{2500}$ is related to the vegetation scheme. In Figure 1 the triangles show results from all experiments using the MOSES1 vegetation scheme (with timeslabs 1 and 2.5 showing results from Plio $_{\text {Bragg }}$ and Preind ${ }_{\text {Bragg }}$ and timeslabs 3-6 showing results from the continuation Plio $_{\text {Bragg-add }}$ and Preind Bragg-add $_{\text {. }}$. All MOSES2-TRIFFID experiments based on Plio $_{2500}$ and Preind 2500 are shown by stars. 

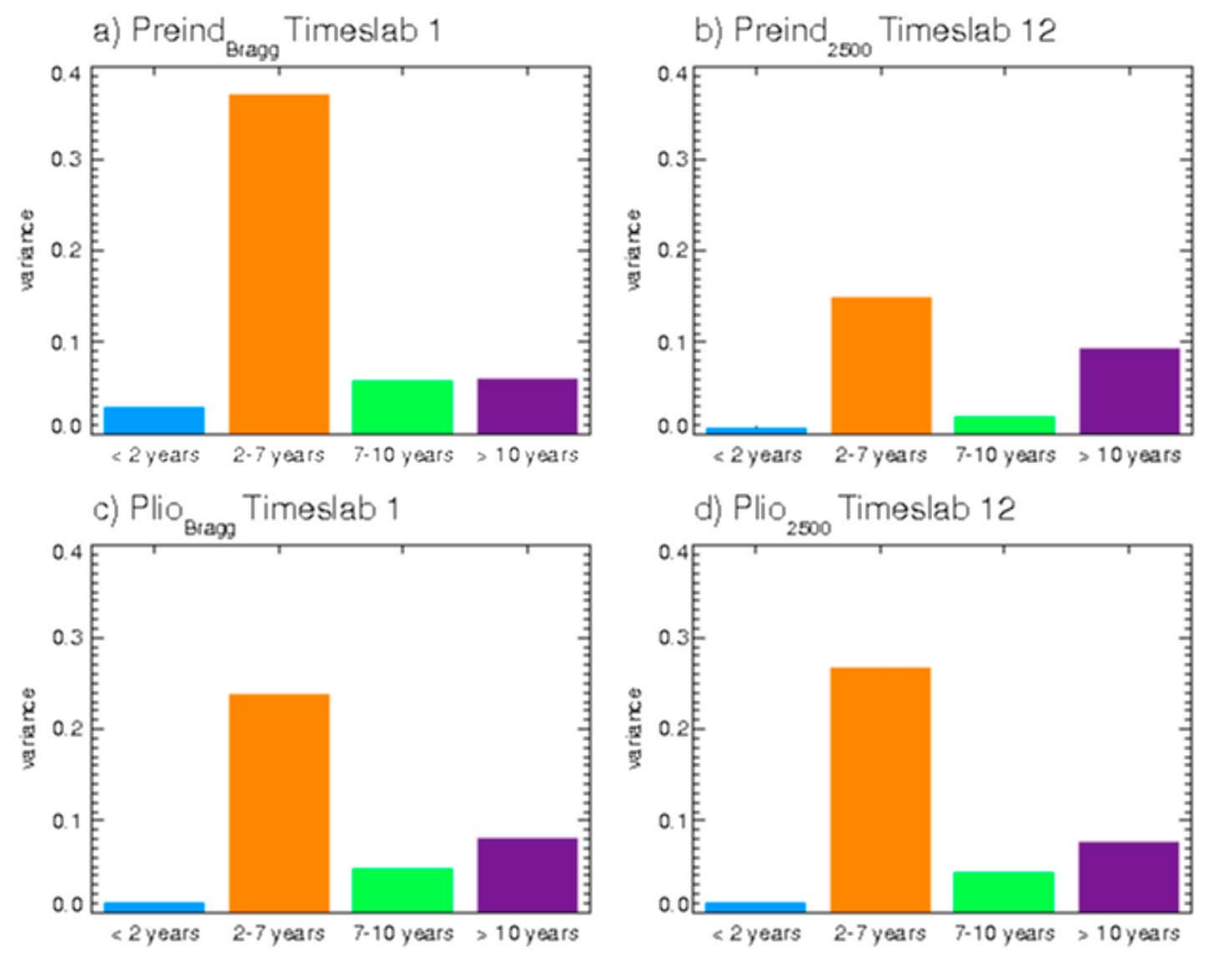

Figure 2. Periods of variability that determine the variance in the NINO3.4 region for the ( $a$ and $b)$ preindustrial and (c and d) Pliocene. MOSES1 results from timeslab 1 are shown in Figures 2a and 2c, while MOSES2-TRIFFID results from timeslab 12 are shown in Figures $2 \mathrm{~b}$ and $2 \mathrm{~d}$.

Figure 1 shows that the standard deviation in the NINO3.4 region for Preind ${ }_{\text {Bragg }}$ (blue triangles) was consistently higher than for Preind ${ }_{2500}$ (blue stars), and century-scale variability between the NINO3.4 standard deviation for the two vegetation schemes does not overlap. This result is quite concerning as it suggests that the choice of vegetation scheme could have an unreasonably large effect on ENSO behavior. However, when compared with the full range of PlioMIP models [Brierley, 2015] where this metric ranges from $\sim 0.45$ to $1.8^{\circ} \mathrm{C}$, the differences between the two versions of HadCM3 are comparatively small. A preindustrial simulation which uses the MOSES2 vegetation scheme with static vegetation derived from the Salzmann et al. [2008] data set (blue diamonds in Figure 1) shows similar variability in the NINO3.4 region to the MOSES2 simulation with dynamic vegetation $\left(\operatorname{Preind}_{2500}\right)$. This is despite the fact that the land surface conditions in the static vegetation simulation are intended to represent the same land surface conditions that are in Preind Bragg. $_{\text {. }}$ it is also seen that for MOSES1 the preindustrial NINO3.4 standard deviation is usually larger than the Pliocene, while in the MOSES2-TRIFFID simulations the situation is reversed. This leads to the rather unsatisfactory suggestion that whether the model suggests weaker or stronger ENSO variability in the Pliocene is dependent on the vegetation scheme.

Not all of the variance in the NINO3.4 region can necessarily be related to ENSO, however. Both longer-period variability, perhaps related to the Pacific Decadal Oscillation [Mantua and Hare, 2002; Zhang et al., 1997], or shorter-period variability could contribute. Figure 2 shows the variance in the NINO3.4 region partitioned into contributing periods for Preind $\mathrm{Bragg}_{\text {Plio }} / \mathrm{Plagg}_{\text {Brag }}$ at timeslab 1 (MOSES1) and $\mathrm{Preind}_{2500} / \mathrm{PliO}_{2500}$ at timeslab 12 (MOSES2-TRIFFID). The variance partitioning is similar for both Pliocene simulations (Figures $2 \mathrm{c}$ and $2 \mathrm{~d}$ ); however, there is a reduction in variance between Preind ${ }_{\text {Bragg }}$ and Preind ${ }_{2500}$ which is related to ENSO periodicities of 2-7 years. This shows that the changes in variance between the preindustrial and Pliocene are due to changes at ENSO periodicities, which is likely due to changes in ENSO behavior. Here this shows reduced ENSO variability in the Pliocene (when compared to preindustrial) for MOSES1 (Figures 2a and 2c) and increased ENSO variability in the Pliocene for MOSES2 (Figures $2 \mathrm{~b}$ and $2 \mathrm{~d}$ ). However, this is not always the case; there are times when the MOSES1 simulation shows increased ENSO variability in the Pliocene (e.g., timeslab 3.5, triangles in Figure 1) and times where the MOSES2-TRIFFID simulation shows ENSO variability to be reduced in the Pliocene. 


\subsection{Spin-Up, Simulation Length, and Centennial-Scale Variability}

One reason to study a climate such as the Pliocene is to understand the equilibrium state of a world with higher than preindustrial $\mathrm{CO}_{2}$. However, it can take a model simulation of several millenia in order to fully spin-up the whole climate system including the deepest ocean. $\mathrm{Plio}_{2500}$ was started from preindustrial conditions and has run for 2500 years, far in excess of the 500 years required for PlioMIP [Haywood et al., 2011], and although now close to equilibrium with no drift in average ocean temperatures down to $500 \mathrm{~m}$, and drifts below this level reduced relative to the start of the simulation, a small drift in deepest ocean temperature of $0.07^{\circ} \mathrm{C} /$ century remains. In this section we discuss whether the extent of model spin-up could affect the modeled representation of ENSO and also discuss centennial-scale ENSO variability.

Red and Blue stars in Figure 1 represent 200 year subsets of $\mathrm{PliO}_{2500}$ and Preind ${ }_{2500}$. (The first Pliocene times$\mathrm{lab}$ is not included in this figure since it is dominated by a warming trend as the climate adapts to the Pliocene boundary conditions.) Timeslabs 2-8, representing years 200-1800 of the simulations, do not provide a clear consensus on whether ENSO was weaker or stronger in the Pliocene. Only from timeslab 9 onward (corresponding to model years 1800-2500) is there a consistently stronger ENSO signal in the Pliocene relative to the preindustrial.

Plio $_{\text {Bragg }}$ and Plio $_{\text {Bragg-add }}$ (red triangles) were run with PRISM3D boundary conditions, but Plio ${ }_{\text {Bragg }}$ was initialized from the end of a PRISM2 experiment [Lunt et al., 2012] which had run for 1000 years. The red triangles in Figure 1 therefore represent a 2000 year Pliocene simulation, but only 1000 years had consistent PRISM3D boundary conditions. It is unclear whether this experiment should then be compared to the earlier or later timeslabs of $\mathrm{Plio}_{2500}$ for maximum consistency. If $\mathrm{Plio}_{\mathrm{Bragg}}$ and $\mathrm{Plio}_{\mathrm{Bragg}-\text { add }}$ are compared with years 200-1800 of $\mathrm{PliO}_{2500}$, the results are in greatest agreement and are consistent with ENSO behavior being generally weaker in the Pliocene than in the preindustrial. However, it can be argued that the later stages of Plio ${ }_{2500}$, where ENSO was stronger, are most accurate since this is closer to an equilibrium state and should be used in preference to results from an earlier stage if there is disagreement.

Despite a consideration of simulation length leading to increased consistency between the Bragg et al. [2012] and 2500 year experiments, this is still not sufficient to fully explain the differences between the two

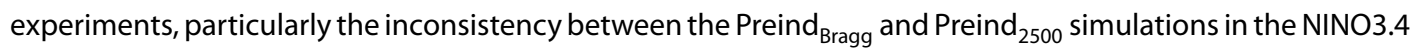
standard deviation. It appears that a combination of run length, large centennial-scale variability, and a slightly different model setup combines to explain the difference in the NINO3.4 standard deviation, although this cannot be fully verified by the present study. However, at the start of this section it was noted that ENSO behavior is not always inconsistent between these simulations and robust changes in ENSO behavior between the Pliocene and the preindustrial can be found. In the next section we will expand our attention to focus on some other ways of measuring ENSO, to assess more fully the extent to which the simulations do truly differ. We will discuss how much of the change in ENSO behavior is due to the metric used and provide a more robust way of determining whether El Niño was stronger or weaker in the Pliocene. Bellenger et al. [2014] used a large number of metrics to compare model simulations of ENSO, and the limited focus on the standard deviation in the NINO3.4 region used so far may detract from the bigger picture.

\section{Other ENSO Metrics}

\subsection{Amplitude, Frequency, and Duration of El Niño and La Niña}

The next metric of El Niño to be considered is based on the Oceanic Nino Index (ONI), which is used by NOAA's Climate Prediction Center. The ONI is the 3 month running mean SST anomaly in the NINO3.4 region; a warm episode (El Niño) is said to occur when the ONI exceeds a threshold of $+0.5^{\circ} \mathrm{C}$ for at least five consecutive months, while a cold episode occurs when the $\mathrm{ONI}$ is below $-0.5^{\circ} \mathrm{C}$ for at least five consecutive months. The average amplitude of all El Niño events as determined by the ONI calculated separately for each 200 year timeslab is shown in Figure 3 (top) (note that the SST anomalies used to calculate the ONI were obtained by removing the average annual cycle of the timeslab). This metric of ENSO gives results that are consistent with the standard deviation in the NINO3.4 region. It suggests that, in general, Plio $_{\text {Bragg }}$ experiments show weaker than modern El Niño, while Plio $_{2500}$ experiments show stronger than modern El Niño, albeit with some uncertainties introduced by run length and centennial-scale variability. However, this metric suggests more overlap between the Bragg et al. [2012] experiments and the 2500 year experiments than suggested by the NINO3.4 standard deviation and reduces the variability between timeslabs in both the Pliocene and the preindustiral. A two-sided $t$ test to assess whether the ENSO3.4 amplitude differs between the Pliocene and the preindustrial 

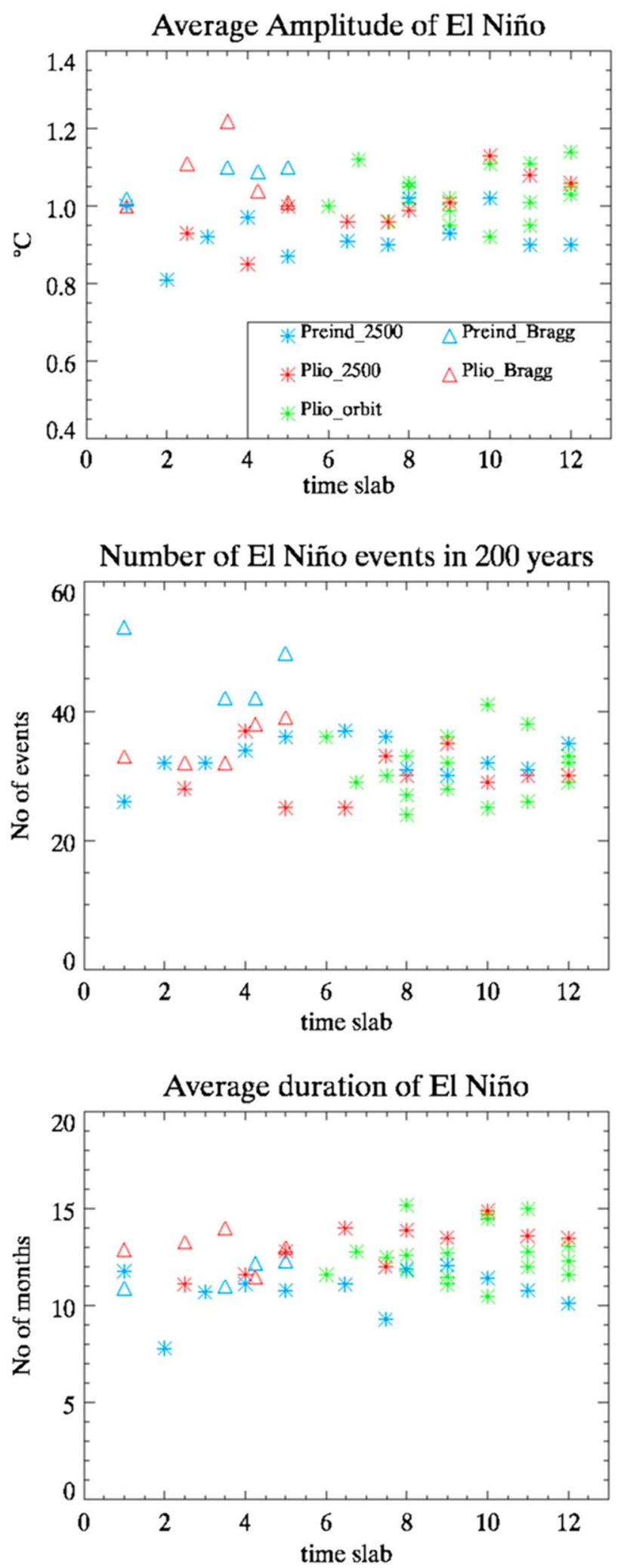

Figure 3. Average amplitude, frequency, and duration of El Niño episodes derived using the ONI based on the NINO3.4 region. Triangles are MOSES1 simulations based on [Bragg et al., 2012], stars are MOSES2-TRIFFID simulations based on the 2500 year simulations, and diamonds show MOSES2 simulations with static vegetation. Each time slab represents a consecutive 200 year subset of each simulation. The green stars show the range of MOSES2-TRIFFID simulations with orbits ranging from $3.185 \mathrm{Ma}$ to $3.225 \mathrm{Ma}$. 
gives $p=0.0825$, which is much lower than that calculated for NINO3.4 standard deviation $(p=0.44)$ but is still not significant at the $5 \%$ confidence level.

Figure 3 (middle) shows the frequency of El Niño occurence for all the experiments as defined by the number of distinct events in each 200 year period. Here there is greater consistency between the experiments, with $80 \%$ of paired experiments, showing that El Niño events occurred less frequently in the Pliocene, and a significant ( $p=0.049$ ) difference between Pliocene and preindustrial. For the frequency of El Niño there initially appears to be some influence of the orbital configuration, as both timeslabs 10 and 11 show that one of the alternative Pliocene orbital configurations has higher than preindustrial El Niño frequency. However, the high frequency on timeslab 10 is from the orbit at $3.225 \mathrm{Ma}$, while the high frequency at timeslab 11 is from the orbit representing 3.195 Ma. These orbital scenarios do not exhibit a substantially increased frequency of El Niño at other times; hence, there is not a notable effect of the orbit on the frequency of El Niño.

Figure 3 (bottom) shows the average duration of El Niño events in each timeslice, as defined by the average number of consecutive months which are categorized as El Niño by the ONI threshold criteria. Although there is centennial-scale variability in this metric for both the Pliocene and the preindustrial, nearly all of the paired experiments show that El Niño lasted longer in the Pliocene. A two-sided $t$ test on this metric gives a highly significant difference $(p<0.0001)$ between the Pliocene and the preindustrial, meaning that it is virtually certain that HadCM3 simulates a longer-lasting Pliocene El Niño, providing high intramodel consistency as to Pliocene El Niño behavior. An analysis of La Niña (supporting information Figure S2) suggests little difference between the Pliocene and the preindustrial La Niña signal in the NINO3.4 region. La Niña has similar duration and frequency in both climates (albeit with centennial-scale variability). La Niña amplitude was generally reduced in the Pliocene relative to the preindustrial; however, timeslabs 11 and 12 (corresponding to model years 2000-2400) show that La Niña amplitude increased.

\subsection{Climate Patterns Associated With El Niño}

Although looking at individual metrics as a measure of El Niño can provide useful information, it is also useful to look at climate patterns associated with an El Niño event and how these differ between the Pliocene and the preindustrial. We will now consider ENSO-related differences in Pacific wide temperatures and also Pacific wide precipitation which is one of the most important features of ENSO in terms of climate impacts.

To evaluate centennial-scale variability in El Niño-related climate patterns for the Pliocene and preindustrial, we will consider four paired 200 year subsets of the experiments which Figures 1 and 3 suggest cover the range of El Niño behavior. We consider the $\mathrm{Plio}_{\text {Bragg-add }}$ simulation at timeslab 3.5 (triangles) and the $\mathrm{Plio}_{2500}$ simulation at timeslab 11 (stars), which both show stronger El Niño in the Pliocene. We also consider the Plio $_{\text {Bragg-add }}$ simulation at timeslab 5 (triangles) and the Plio $_{2500}$ simulation at timeslab 4 (stars) which both show weaker El Niño in the Pliocene.

Figures $4 \mathrm{a}, 4 \mathrm{c}, 4 \mathrm{e}$, and $4 \mathrm{~g}$ show the El Niño anomaly in the Pliocene as defined by a composite of all El Niño conditions minus a composite of all "normal" (neither El Niño nor La Niña) conditions. The composites are derived using all months where El Niño is determined from the ONI as defined in section 4.1; however, it is noted that some individual months where the $\mathrm{ONI}>+0.5^{\circ} \mathrm{C}$ could be included in the normal composite, since the threshold must be exceeded for five consecutive months for a month to qualify as an El Niño. The El Niño and normal composites are weighted by the relative frequency of occurrence in each calendar month, so that each calendar month contributes equally to the composite, and the anomaly is representative of an annual average. In Figures 4b, 4d, 4f, and $4 \mathrm{~h}$ the difference between the Pliocene El Niño anomaly and the preindustrial El Niño anomaly is shown. Despite the fact that we have chosen timeslabs intended to represent a large range of behavior and that a focus on the NINO3.4 region suggested large centennial-scale variability in El Niño, the results from Figure 4 show a reasonably coherent pattern. All timeslabs show an increase in the temperature in the central Pacific combined with a cooling in the northwest part of the region and near Australia. However, the temperature response in the NINO3.4 region (see marked box in Figure 4) varies depending on the timeslab, and although it is not representative of the Pacific, it causes the inconsistent results shown in Figures 1 and 3 (top). Figure 4 suggests that the main climate patterns are robust and that Pliocene El Niño was stronger and shifted toward the west relative to the preindustrial.

To highlight this further, Figure 5 is analogous to Figure 4 but showing the Pliocene precipitation El Niño anomaly and how it differs from the preindustrial. With the exception of the $\mathrm{Plio}_{2500}$ experiment at timeslab 4 (Figures $5 e$ and $5 f$ ) where patterns are weak, all simulations predict an intensification of the precipitation 
(a) Plio $_{\text {Bragg }}$; Timeslab 3.5

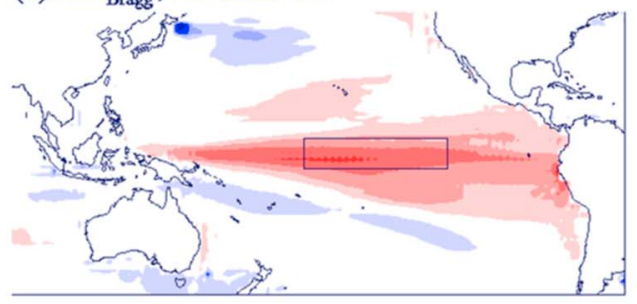

(c) Plio $_{\text {Bragg }}$; Timeslab 5

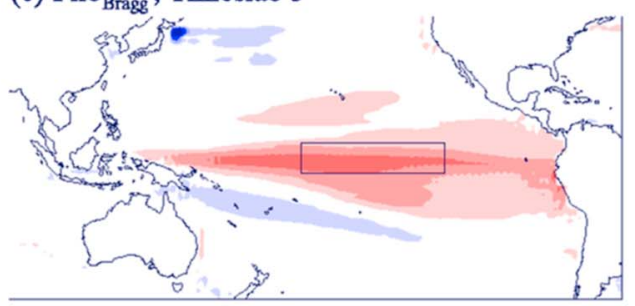

(e) Plio $_{2500}$; Timeslab 4

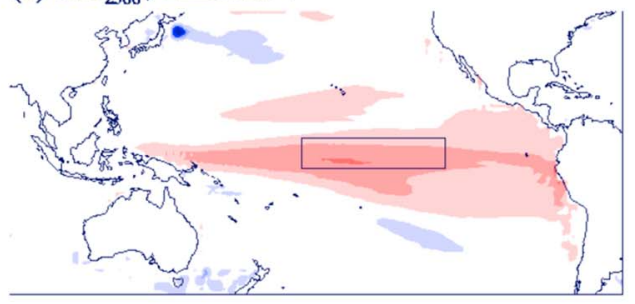

(g) $\mathrm{Plio}_{2500}$; Timeslab 11

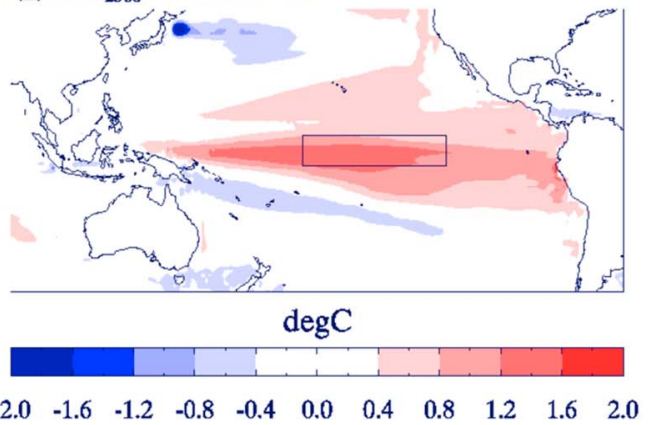

(b) Plio $_{\text {Bragg }}$ - Preind ${ }_{\text {Bragg }}$; Timeslab 3.5

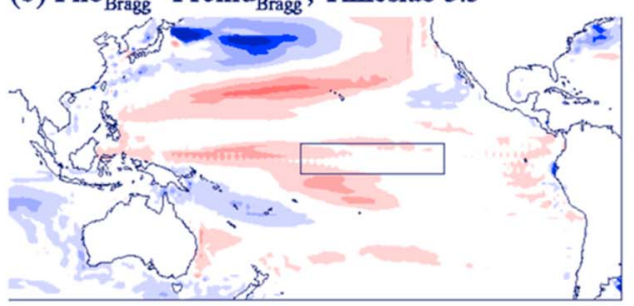

(d) $\mathrm{Plio}_{\text {Bragg }}$ - Preind ${ }_{\text {Bragg }}$; Timeslab 5

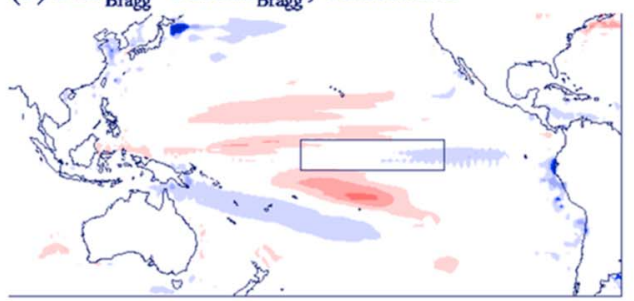

(f) $\mathrm{Plio}_{2500}-$ Preind $_{2500}$; Timeslab 4

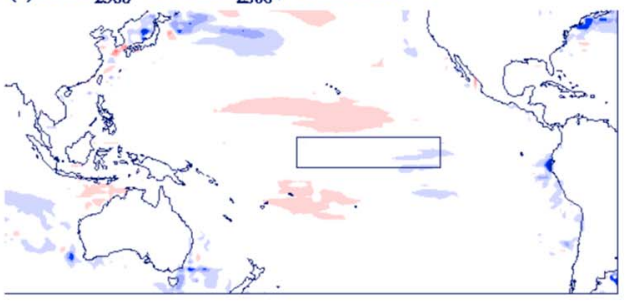

(h) Plio $_{2500}$ - Preind ${ }_{2500}$; Timeslab 11

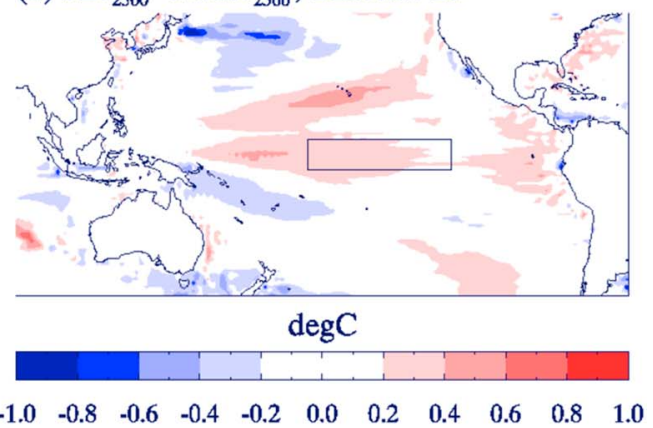

Figure 4. (a, c, e, and g) The Pliocene El Niño temperature signal (as defined by composite El Niño temperature minus composite normal temperature). (b, $d, f$, and $h$ ) The difference between the Pliocene El Niño temperature signal and the preindustrial El Niño temperature signal. Each row shows data from a different 200 year timeslab.

patterns associated with El Niño in the Pliocene, regardless of the simulation setup. The effect of intramodel centennial-scale variability on EI Niño therefore appears to be limited to a small region, which affects NINO3.4 diagnostics, and is of limited importance when viewed in the context of the whole Pacific.

Although removing focus from the NINO3.4 region means that the timeslabs now agree in the sign of the change of Pliocene El Niño, there remains notable centennial-scale differences in the magnitude of this change. For example, in contrast to most other timeslabs, $\mathrm{Plio}_{2500}$ timeslab 4 (Figures 4e, 4f, $5 \mathrm{e}$, and 5f) shows very little change in either the El Niño temperature or precipitation anomalies between the Pliocene and preindustrial. Reasons for this centennial variability will now be investigated.

\subsubsection{El Niño Modoki}

While the precipitation change (Figures $5 b, 5 d, 5 f$, and $5 h$ ) coincides with the region of maximum El Niño precipitation signal (Figures 5a, 5c, 5e, and 5g), for temperature this is not the case. The Pliocene-preindustrial El Niño anomaly is shifted from the eastern Pacific and is more prominent in the central and western Pacific; this 
(a) Plio ${ }_{\text {Bragg }}$; Timeslab 3.5

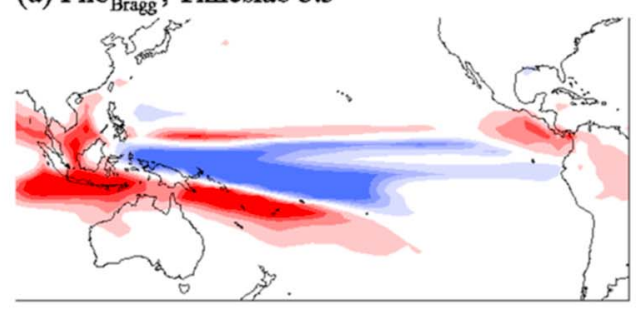

(c) Plio $_{\text {Brags }}$; Timeslab 5

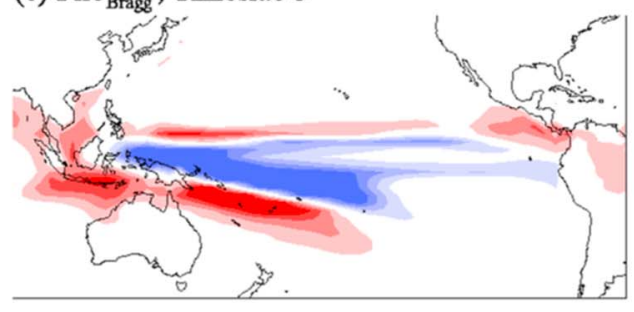

(e) Plio $_{2500}$; Timeslab 4

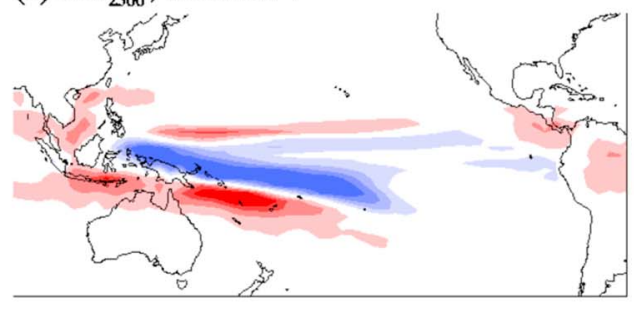

(g) $\mathrm{Plio}_{2500}$; Timeslab 11

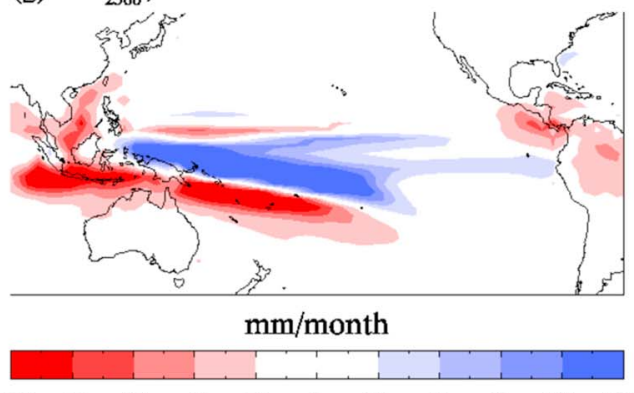

(b) Plio $_{\text {Bragg }}$ - Preind ${ }_{\text {Bragg }}$; Timeslab 3.5

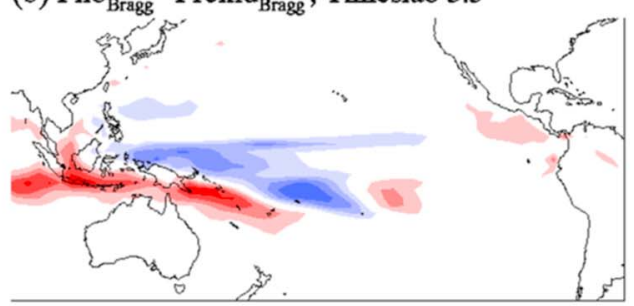

(d) Plio $_{\text {Bragg }}-$ Preind $_{\text {Bragg }}$; Timeslab 5

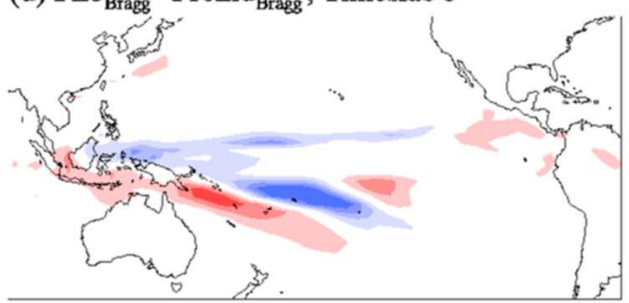

(f) Plio $_{2500}-$ Preind $_{2500}$; Timeslab 4

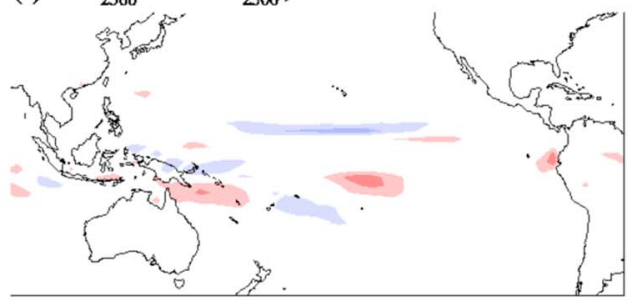

(h) Plio $_{2500}$ - Preind ${ }_{2500}$; Timeslab 11

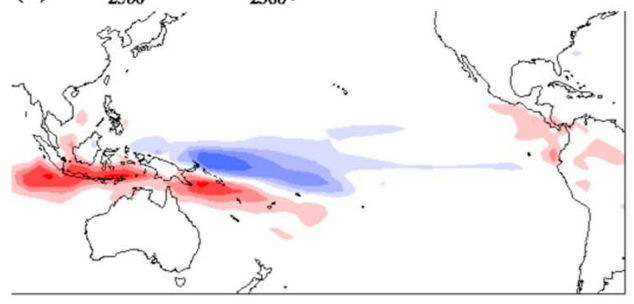

$\mathrm{mm} / \mathrm{month}$

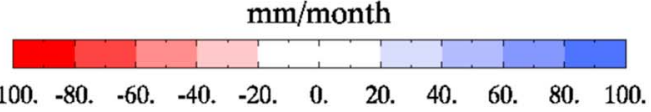

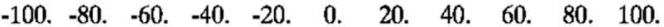

Figure 5. (a, c, e, and g) The Pliocene El Niño precipitation signal (as defined by composite El Niño precipitation minus composite normal precipitation). (b, $d, f$, and $h$ ) The difference between the Pliocene El Niño precipitation signal and the preindustrial El Niño precipitation signal. Each row shows data from a different 200 year timeslab.

shift is suggestive of the El Niño Modoki signal that is becoming more common in the modern [e.g., Ashok et al., 2007]. In a classic El Niño Modoki the anomalous warming is concentrated in the central Pacific near the dateline with cooling in the eastern and western Pacific. However, the canonical and Modoki flavors of El Niño need not be distinct, and instead, El Niño can occur as a continuum of different types [Capotondi et al., 2015; Johnson, 2013], with different El Niño flavors even being possible within a single event [Karnauskas, 2013]. A shift of the canonical-Modoki continuum could affect metrics focused on a given region (e.g., the NINO3.4 region) and could make an alternative region (e.g., the NINO4 region) more relevant for detecting El Niño changes. Although the NINO3.4 region shows a contrasting temperature signal in Figures $4 \mathrm{~d}$ and $4 \mathrm{~h}$, both figures show the majority of the increased warming in the central Pacific consistent with a shift toward Modoki. The main difference between the two is in the eastern Pacific (cooling in Figure 4d and warming in Figure 4h) which may be due to either century-scale variability in the structure of El Niño or some stochastic behavior in the exact canonical/Modoki ratios. Either way, a shift toward El Niño Modoki is likely to contaminate detec- 
tion of El Niño events in the warm climate of the Pliocene in HadCM3, if the focus is limited only to the NINO3.4 region.

Ashok et al. [2007] looked at the relationship between El Niño Modoki and precipitation patterns (see their Figure 11) and found that in the tropical eastern Pacific the Modoki was associated with drier conditions while the canonical El Niño was associated with wetter conditions. In the central and western Pacific, however, both flavors of El Niño showed wetter conditions near the equatorial dateline and drier conditions to the east of Australia. The precipitation anomalies shown in Figures 4 and 5 are consistent with a shift toward Modoki. It is unclear to what extent this change in El Niño structure is limited to HadCM3 as HadCM3 shows a relatively strong shift toward Modoki compared to other models under future climate change scenarios [Yeh et al., 2009]. However, Brierley [2015] noted that two thirds of the PlioMIP ensemble also suggested that El Niño Modoki was relatively more prevalent in the Pliocene, meaning that a possible shift in the structure of El Niño should therefore be considered when collecting and interpreting paleodata for Pliocene El Niño studies.

\subsubsection{Correlation Between EI Niño and the PDO}

Another important influence on the tropical Pacific is the Pacific Decadal Oscillation (PDO) [Mantua and Hare, 2002; Zhang et al., 1997]. This oscillation has positive phase characterized by cooling in the northwest Pacific, warming in the northeast Pacific, and an El Niño-like signal in the tropics (the negative phase shows the opposite pattern). To avoid contamination by ENSO, the PDO index is defined as the leading empirical orthogonal function (EOF) of monthly SSTA over the North Pacific (poleward of $20^{\circ} \mathrm{N}$ ). Since the PDO and ENSO both affect the tropical Pacific (albeit while operating on different timescales and with different spatial patterns), the PDO interacts with ENSO, with the positive phase of the PDO associated with enhanced frequency of El Niño [Verdon and Franks, 2006]. The PDO can also affect El Niño teleconnections [Power et al., 2006; Chan and Zhou, 2005]. The difference between the Pliocene El Niño temperature signal and the preindustrial El Niño temperature signal (right plots on Figures $4 b, 4 d, 4 f$, and $4 \mathrm{~h}$ ) is very similar to the positive phase of the PDO in $\mathrm{HadCM} 3$, (supporting information Figures $3 \mathrm{a}$ and $3 \mathrm{~b}$ ). It is therefore logical to investigate changes in the PDO and its relationship with ENSO for the Pliocene and the preindustrial throughout these simulations.

Oshima and Tanimoto [2009] found that CMIP3 models had variable skill in reproducing the PDO patterns and amplitude. Using their metric, HadCM3 was shown to have high skill and was ranked fourth out of the 18 models considered. They also found that $\mathrm{HadCM} 3$ was able to reproduce the extratropical linkage associated with the PDO, in particular the relationship between the PDO index (determined by applying a 5 year running mean to SSTA over the central North Pacific region $\left(30-45^{\circ} \mathrm{N}, 150^{\circ} \mathrm{E}-150^{\circ} \mathrm{W}\right)$ ) and the decadal-ENSO index (determined by applying a 5 year running mean to SSTA over the NINO3.4 region). However, the correlation between the PDO and decadal-ENSO index was slightly weaker in $\operatorname{HadCM} 3(r \approx-0.32)$ than in observations $(r=-0.53)$. Brierley [2015] showed that the PlioMIP simulations were not consistent as to whether the PDO was stronger or weaker in the Pliocene; however, in HadCM3 it was found to be stronger. Here we define PDO strength as the spatial standard deviation of the PDO pattern (supporting information Figures $3 a$ and $3 b$ ). The PDO pattern was obtained by multiplying the first EOF of North Pacific temperature (north of $20^{\circ} \mathrm{N}$ ) by the standard deviation of its principal component, such that the associated PDO index would have a standard deviation of 1 . Using this method, we find a consistent increase in Pliocene PDO strength relative to the preindustrial throughout all simulations, which occurs regardless of spin-up or vegetation scheme (see supporting information Figure 3c). However, we find that there is some century-scale variability in the strength of the PDO in both the Pliocene and the preindustrial. On average the HadCM3 Pliocene PDO is $\approx 16 \%$ stronger than preindustrial.

In HadCM3 we do not find any relationship between the average strength of the PDO in a 200 year timeslab and average El Niño conditions (strength, duration, or frequency) in that 200 year timeslab. However, there is a strong relationship between the PDO and ENSO within a timeslab (representative of interannual to multidecadal timescales). The correlation between the NINO3.4 index and the PDO index for the Plio $_{2500}$ simulation at timeslab 11 is shown in Figure 6; here it is seen that the NINO3.4 index leads the PDO index by approximately 6 months. Although the cause of the PDO is currently not known, this correlation is consistent with studies such as Newman et al. [2003] and Schneider and Cornuelle [2005] which are able to model the PDO using ENSO as a strong contributor and "reemergence" of North Pacific SSTs in subsequent winters enabling the difference in timescales between the two phenomena. Every Pliocene and preindustrial timeslab in this study has an ENSO-PDO correlation shape similar to that seen in Figure 6. However, the strength of the correlation varies. A stronger correlation between the PDO and ENSO within a timeslab (meaning that the two are more likely to occur simultaneously) is coincident with a larger average ENSO amplitude within the timeslab. Table 2 shows 


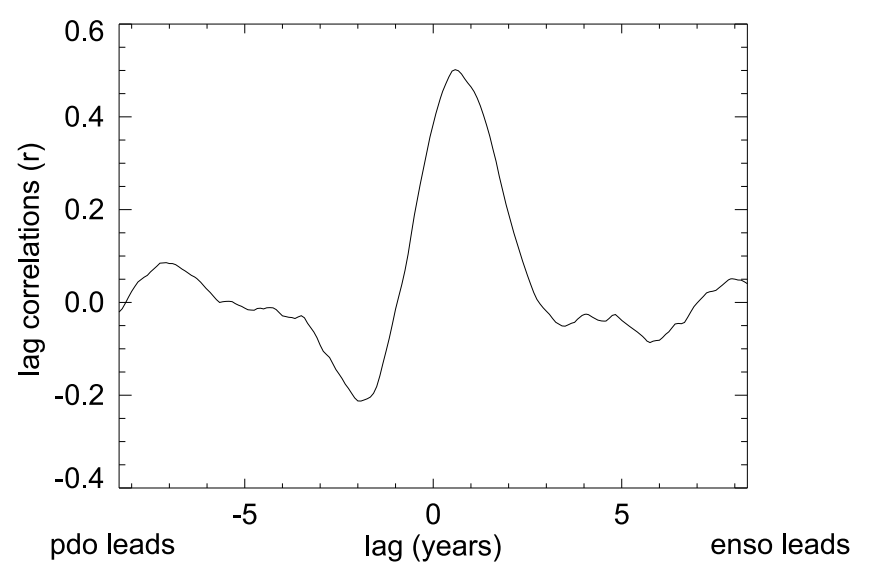

Figure 6. The lag correlation between the ENSO3.4 index and the PDO index for the $\mathrm{PliO}_{2500}$ experiment at timeslab 11.

the strength of the maximum lag correlation for each of the experiments considered in this section; it also provides a qualitative indication of the amplitude of the Pliocene minus preindustrial El Niño anomaly. It is seen that generally, the relationship between ENSO and the PDO is stronger in the Pliocene than in the preindustrial. However, centennial-scale variability means that this is not always the case. The Plio $_{2500}$ experiment at timeslab 4, which showed a particularly weak Pliocene-preindustrial anomaly in Figures 4 and 5, provides a rare example of the PDO-ENSO relationship being weaker in the Pliocene. Although it is beyond the scope of this paper to discuss the relationship between the PDO and ENSO in further detail and why this varies, it is likely that part of the difference in the structure and teleconnections of ENSO between the preindustrial and the Pliocene is due to the PDO and its relationship with ENSO.

Krapp and Jungclaus [2015] studied the relationship between the PDO and ENSO in a simulation of the Miocene climate, where $\mathrm{CO}_{2}$ levels were set to 720 ppm. They found that at high $\mathrm{CO}_{2}$ levels, spectral coherence between the PDO and ENSO converged sufficiently that they could be treated as a single mode of Pacific variability. They suggested that this was related to Miocene El Niño patterns becoming more Modoki, which increased teleconnections between the tropics and the extratropics. Our study of the Pliocene has a more modest $\mathrm{CO}_{2}$ increase (405 ppm) and shows changes in ENSO and the PDO that are consistent with, but less extreme than, those of the Miocene reported by Krapp and Jungclaus [2015]. In our Pliocene simulation, ENSO and the PDO do not converge to a single mode, yet we do find a lower frequency ENSO which is more strongly correlated with the PDO. These Pliocene simulations, with forcing intermediate between the preindustrial and Miocene simulations of Krapp and Jungclaus [2015], show ENSO and the PDO changes that are between the extremes suggested by Krapp and Jungclaus [2015], providing consistent results as to how these phenomena would appear in a warmer world. Consistent with Krapp and Jungclaus [2015], the Pliocene simulations also show the shift toward Modoki which was related to the increased coherence between the tropics and the extratropics and the stronger correlation between ENSO and the PDO.

The PDO needs to be accounted for in order to understand long-term ENSO variability in past climates in the same way this is needed for the modern. The PDO varies on longer timescales than modern ENSO, can amplify ENSO signals, and can explain some of the difference in amplitude and frequency both within a single simulation and between different climates.

Table 2. Maximum Lag Correlation ( $r$ ) Between the ENSO Index and the PDO Index

\begin{tabular}{|c|c|c|c|}
\hline \multirow{2}{*}{$\begin{array}{l}\text { Experiment } \\
\text { and Timeslab }\end{array}$} & \multicolumn{2}{|c|}{ PDO Versus ENSO Correlation } & \multirow{2}{*}{$\begin{array}{l}\text { Pliocene-Preindustrial } \\
\text { El Niño Anomaly }\end{array}$} \\
\hline & Pliocene & Preindustrial & \\
\hline Timeslab 3.5 Bragg-add & 0.41 & 0.29 & Large \\
\hline Timeslab $5_{\text {Bragg-add }}$ & 0.42 & 0.33 & Intermediate \\
\hline Timeslab $4_{2500}$ & 0.33 & 0.37 & Small \\
\hline Timeslab $11_{2500}$ & 0.50 & 0.23 & Large \\
\hline
\end{tabular}



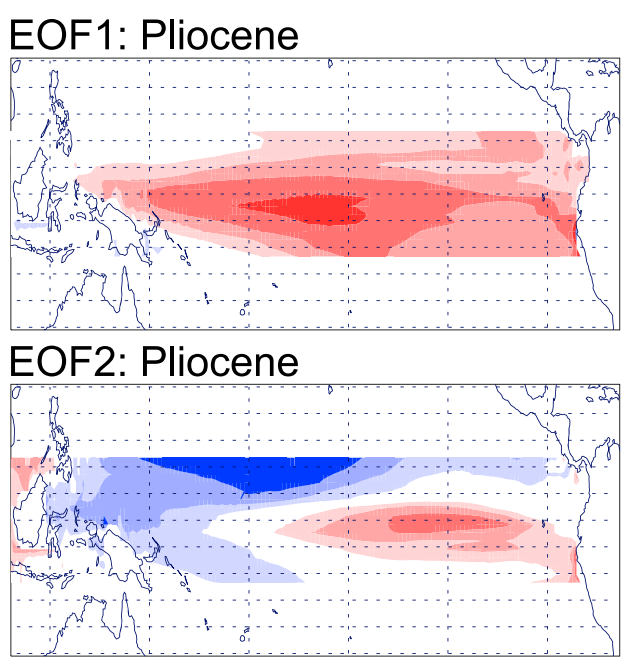

EOF3: Pliocene

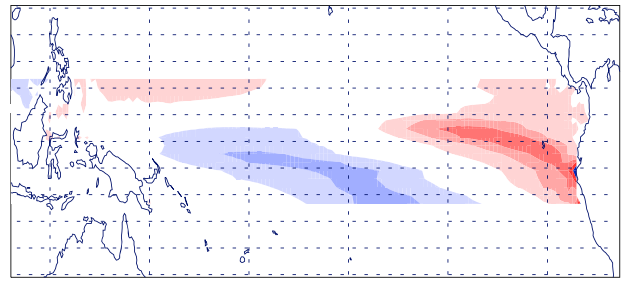

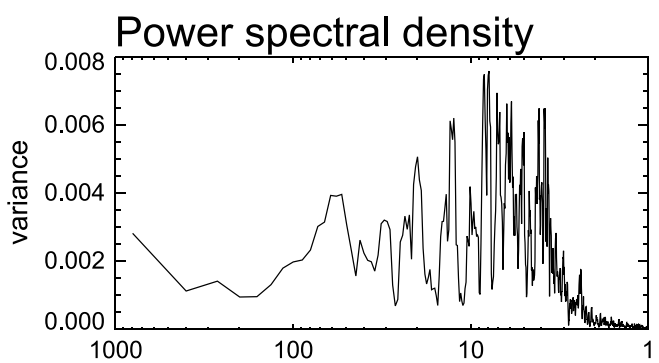
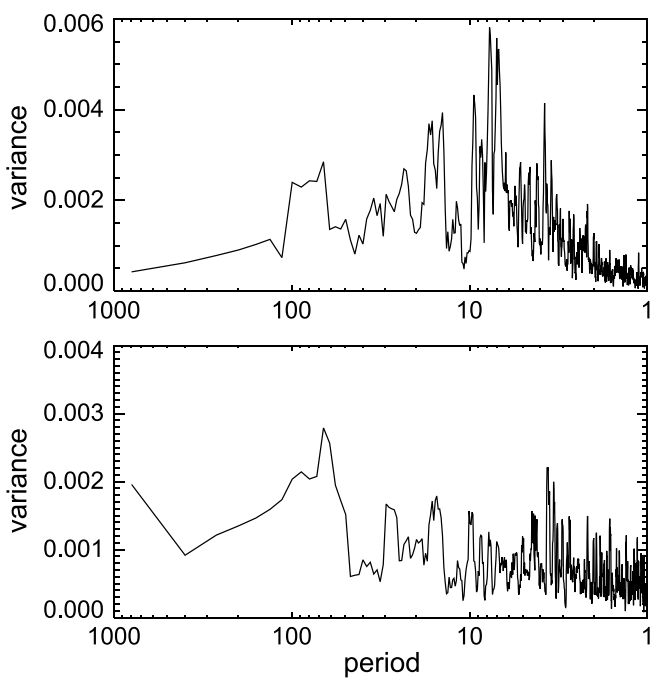

Figure 7. (left column) The first three EOFs of the final 700 years of Plio $_{2500}$, calculated over the tropical Pacific between $10^{\circ} \mathrm{N}$ and $10^{\circ} \mathrm{S}$. These explain $48 \%, 8 \%$, and $5 \%$ of the variability in the region, respectively. (right column) The power spectral density function for each EOF, showing the periods of variability over which each EOF is important.

\subsubsection{Multidecadal to Centennial Variability in the Tropical Pacific}

Figure 7 shows the first three EOFs of tropical Pacific variability obtained for the final 700 years of the Plio 2500 simulation. These respectively explain $48 \%, 8 \%$, and $5 \%$ of the interannual variability in the region $10^{\circ} \mathrm{N}-10^{\circ} \mathrm{S}$, $110^{\circ} \mathrm{E}-70^{\circ} \mathrm{W}$. They are typical of the modes of variability for both the preindustrial and Pliocene simulations. However, the first EOF is stronger in the central Pacific in the Pliocene than in the preindustrial. None of the EOFs show a pure "canonical" or "Modoki" El Niño pattern, but the first EOF clearly represents El Niño and is very similar to the El Niño signal in Figure 4. The first EOF is characterized by a warming across the Pacific, which is likely a superimposition of both the canonical and Modoki modes. The power spectrum of EOF1 shows peaks at ENSO periods (2-7 years), but also peaks at decadal to multidecadal scales (10-80 years), most likely representing the effects of the PDO in this region. The second and third EOFs together explain only $15 \%$ of the variability in the tropical Pacific but have notable power at multidecadal to centennial scales, particularly EOF3. Both EOF2 and EOF3 show a gradient across the Pacific associated with warming in the eastern Pacific when there is cooling in the western Pacific. EOF2 and EOF3 could (when combined with EOF1) shift the center of an El Niño signal, potentially changing the interpretation of El Niño on the canonical-Modoki continuum on multidecadal to centennial timescales. Both EOF2 and EOF3 affect the NINO3.4 region and could affect the characteristics of El Niño in NINO3.4. EOF2 and EOF3 also affect the NINO4 region; however, EOF1 is stronger in NINO4 and EOF2 is slightly weaker, meaning that long-term variability of EOF2 and EOF3 will have a smaller relative effect on NINO4. As mentioned in the previous section, an increase in the ratio of El Niño Modoki can increase the teleconnections between ENSO and the PDO, which in turn will strengthen the El Niño temperature signal in the tropics. Centennial-scale variability in the canonical-Modoki ratio, as is suggested from Figure 7, could therefore contribute to the centennial-scale variability in the strength of ENSO for the Pliocene and the preindustrial.

\subsection{Pliocene ENSO Variability in NINO4 Region}

When understanding changes in El Niño with time, it can be useful to reduce behavior to a single index so that temporal variability can be clearly seen. The most commonly used indexes for ENSO behavior are based on 


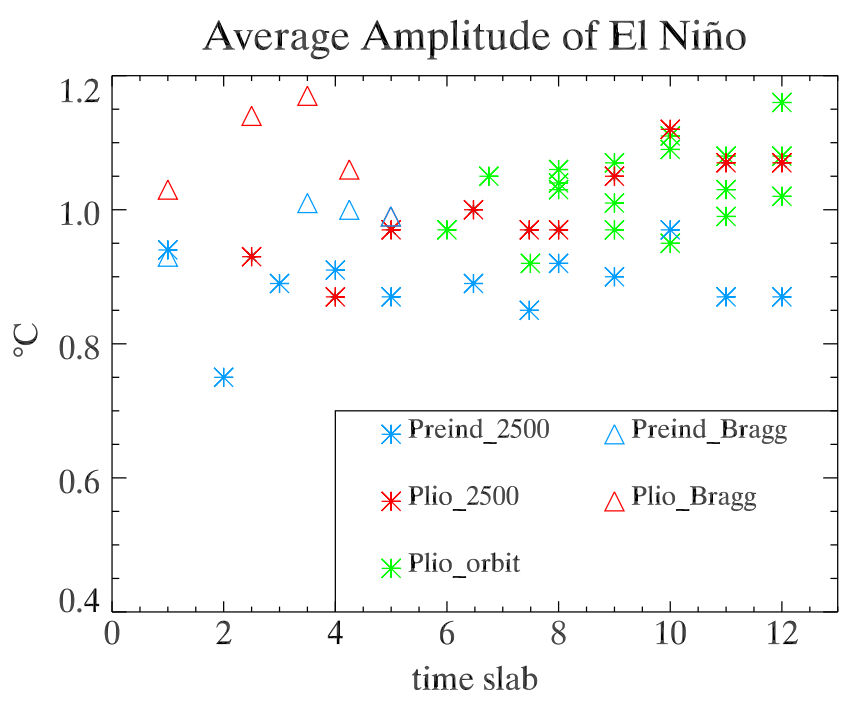

Figure 8. Average amplitude of El Niño episodes in the NINO4 region. Triangles are MOSES1 simulations based on Bragg et al. [2012], and stars are MOSES2-TRIFFID simulations based on the 2500 year experiments. Each time slab represents a consecutive 200 year subset of each simulation. The green stars show the range of MOSES2-TRIFFID simulations with orbits ranging from $3.185 \mathrm{Ma}$ to $3.225 \mathrm{Ma}$.

the NINO3.4 region, since this region encompasses the western half of the cold tongue region and provides a good measure of changes in sea surface temperature and salinity gradients. However, the NINO3.4 region has been chosen based on its relevance for historical climate, and it is possible that metrics based on this region may be less suitable for alternative climates such as the Pliocene, especially if there are changes in ENSO structure or its relationship with other climate phenomena. Since it is impossible to obtain temporally synchronous paleodata of Pliocene age from the whole of the Pacific, and HadCM3 suggests that the NINO3.4 region may not be optimal for detecting changes in El Niño between the Pliocene and preindustrial; we will now consider whether centennial-scale variability on the NINO4 region is more appropriate for understanding changes in Pliocene ENSO.

Figure 8 shows the average amplitude of the El Niño events in the NINO4 region for all timeslabs of all experiments. The El Niño events were reobtained based on NINO4 temperature, and therefore, the years which are determined to be El Niño are not identical to section 3. Unlike the analogous figure for NINO3.4 (Figure 3, top),

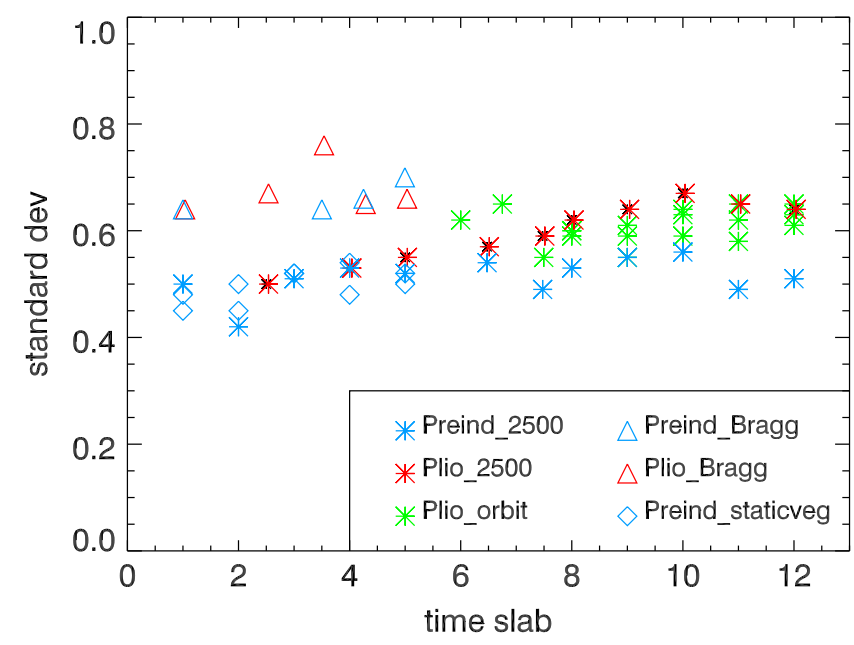

Figure 9. Standard deviation in the NINO4 region (after smoothing with a Lanczos low-pass filter of 18 months). Triangles are MOSES1 simulations based on Bragg et al. [2012], and stars are MOSES2-TRIFFID simulations based on the 2500 year experiments. Each time slab represents a consecutive 200 year subset of each simulation. The green stars show the range of MOSES2-TRIFFID simulations with orbits ranging from 3.185 Ma to $3.225 \mathrm{Ma}$. 
this region shows an increase in average El Niño amplitude for almost all timeslabs. In addition, a $t$ test shows that the change between the two climates is much more significant $(p<0.0001)$ in this region than in the NINO3.4 region $(p=0.0825)$. There are, however, two paired cases where average amplitude in NINO4 was reduced in the Pliocene. The first is the Plio $_{2500}$ and Preind ${ }_{2500}$ experiments at timeslab 4, which was discussed in the previous section as being anomalous and having a nontypical change in the Pliocene relationship between ENSO and the PDO. The second is one of the alternative orbits (namely, $\mathrm{Plio}_{3225}$ ) at timeslab 10, which has slightly weaker amplitude than preindustrial. However, later timeslabs from this orbit are in agreement with the other Pliocene experiments implying that this particular anomaly is due only to centennial-scale variability. It therefore appears that in the NINO4 region, subtle changes to the model setup do not have any impact on determining the strength of El Niño in the Pliocene, and HadCM3 is robustly showing Pliocene El Niño stronger than preindustrial.

Figure 9 shows the standard deviation in the NINO4 region for timeslabs of all experiments. This metric shows slightly less consistent results, despite a significant change between the Pliocene and preindustrial overall $(p=0.007$ ). For this metric, early timeslabs (particularly from the Bragg experiments and also for the 2500 year experiments) show a range of behaviors, including no change, stronger ENSO in the Pliocene, and stronger ENSO in the preindustrial. This is likely due to the standard deviation including a signal of several indicators of ENSO behavior, which may have opposing effects on the standard deviation. For example, we would expect the increase in El Niño amplitude to increase the standard deviation and the reduction in El Niño frequency (Figure 3, middle) to reduce the standard deviation. This means that clear signals (such as amplitude and frequency changes in the NINO4 region) are likely to be obscured in a composite metric such as standard deviation. In the NINO3.4 region the amplitude signal was also not clear and so neither amplitude nor standard deviation showed a robust change between the two climate states, but even in NINO3.4, the likelihood of detecting a change between the two climate states was higher when considering amplitude, instead of standard deviation. In general, the ENSO signals are more consistent across the experiments in the NINO4 region than in the NINO3.4 region, and this has implications for how best to detect changes in ENSO in paleodata.

\section{Discussion and Conclusions}

Many differences between the Pliocene ENSO and the preindustrial ENSO are robust across multimillenial-scale HadCM3 simulations and are not affected by small changes in model setup, despite some centennial-scale variability in the strength of these differences. These differences are that El Niño was detected less frequently but had slightly longer duration in the Pliocene, and when considering Pacific wide signals, El Niño was stronger in the Pliocene in both temperature and precipitation. However, the temperature signal increases more in the central and western Pacific with smaller changes in the east and in the NINO3.4 region.

Despite the bulk of the PlioMIP ensemble suggesting a weaker Pliocene ENSO in the NINO3.4 region [Brierley, 2015], intramodel variability in the HadCM3 model suggests that the real nature of Pliocene ENSO in this region may be more complicated. A combination of simulation length, century-scale variability, and exact model parameters can influence this region in a significant way making it difficult to draw robust conclusions. In HadCM3, looking at the standard deviation over the NINO3.4 region or the amplitude of El Niño events in this region did not give a consistent answer as to whether El Niño was stronger or weaker in the Pliocene and a focus on other diagnostics was needed to understand how ENSO was different. This paper has analyzed simulations using a single model to determine Pliocene El Niño; however, some of the simulations have slightly different model setup (specifically changes in the land surface scheme), which appeared to affect El Niño behavior in the NINO3.4 region. The extent of model spin-up also appeared to affect ENSO characteristics in the NINO3.4 region as this region did show stronger Pliocene El Niño but only after $\approx 1800$ model years. The more robust features of ENSO behavior occurred throughout the simulation and did not require such a long spin-up. Changes in orbital parameters were not found to have a clear affect on even the most subtle aspects of ENSO behavior, implying that ENSO could be assumed to be consistent throughout the period 3.185 Ma-3.225 Ma.

The patterns of temperature change between the Pliocene El Niño signal and the preindustrial El Niño signal are similar to the temperature signal associated with the PDO, suggesting some overprinting of PDO temperature on Pliocene El Niño events. Although the PDO was stronger in the Pliocene, this was not the reason for the overprinting of PDO temperatures; instead, the decadal-scale correlation between ENSO and the PDO 
was important. This is as expected since a high correlation means that the PDO and ENSO are more likely to be in phase, and since they affect some of the same regions, the signal of each will be amplified. The correlation between ENSO and the PDO is stronger in the Pliocene simulation than in the preindustrial simulation, showing stronger teleconnections in the Pliocene world. However, centennial-scale variability in this relationship can occur, and an anomalously weak relationship between ENSO and the PDO can result in the average amplitude of ENSO being anomalously weak. This can lead to individual centuries that contradict the general trend of stronger El Niño in the Pliocene.

The prediction of modern ENSO by models is still not perfect, and models do not provide a unanimous consensus as to what will happen to ENSO variability in the future or how ENSO was different in the past. Therefore, the results suggested in this paper must be taken with caution especially when some of the results (e.g., stronger El Niño in the Pliocene) are not fully in agreement with other models [Brierley, 2015; Zhang et al., 2012]. However, if we are going to use models to make suggestions about past climates, it is important to be certain as to what the modeled suggestions are, including that the signal is visible above low-frequency variability within the preindustrial and that the analysis is focused on the correct diagnostics. In this study a clear signal can be seen above centennial-scale intrinsic variability showing a consistent model prediction for some diagnostics: frequency of El Niño (reduced in the Pliocene), duration of El Niño (longer in the Pliocene), El Niño precipitation amplitude (larger in the Pliocene), and El Niño temperature amplitude in the NINO4 region (larger in the Pliocene). Diagnostics focused on the NINO3.4 region appear inconsistent, for at least the first millennium, and composite diagnostics (e.g., standard deviation) are also difficult to interpret. When considering results from a $t$ test, changes between climate states in the NINO3.4 region had much lower significance than in the NINO4 region regardless of what diagnostic was used. Any shift in the structure (or "flavor") of El Niño, as this paper and Brierley [2015] have suggested for the Pliocene, will change the regions where the strongest signals are detected, and this must be considered when collecting and interpreting paleodata from limited geographical regions. This point is especially important for time periods in the distant past where data are less abundant and suggestions of past climate behavior can be based on limited data.

For the future, model predictions of El Niño changes are inconsistent. A warm period of the past may provide clues as to what ENSO behavior could be expected in a warm future; hence, understanding how to interpret paleodata based on warm past climates is crucial. This paper has shown that interpreting paleodata based on modern climate patterns may not be optimum for warm climates of the past. Such a method may give results that are not reliable. If possible, paleodata from a number of regions and over a millennial scale should be considered to verify the full changes of ENSO between the preindustrial and the Pliocene and to assess whether these changes are consistent.

\section{Acknowledgments}

Research leading to these results has received funding from the European Research Council under the European Union's Seventh Framework Programme (FP7/2007-2013)/ERC grant agreement 278636. The authors would like to thank Anna von der Heydt and two anonymous reviewers for their helpful comments which have greatly improved the manuscript and Steven Pickering for modeling support Data used to produce the results of this paper are attached as supporting information.

\section{References}

Alexander, M., I. Blade, M. Newman, J. Lanzante, N. Lau, and J. Scott (2002), The atmospheric bridge: The influence of ENSO teleconnections on air-sea interaction over the global oceans, J. Clim., 15(16), 2205-2231, doi:10.1175/1520-0442(2002)015<2205:TABTIO>2.0.CO;2.

An, S., and B. Wang (2000), Interdecadal change of the structure of the ENSO mode and its impact on the ENSO frequency, J. Clim., 13(12), 2044-2055, doi:10.1175/1520-0442(2000)013<2044:ICOTSO>2.0.CO;2.

Ashok, K., S. K. Behera, S. A. Rao, H. Weng, and T. Yamagata (2007), El Niño Modoki and its possible teleconnection, J. Geophys. Res., 112, C11007, doi:10.1029/2006JC003798.

Bellenger, H., E. Guilyardi, J. Leloup, M. Lengaigne, and J. Vialard (2014), ENSO representation in climate models: From CMIP3 to CMIP5, Clim. Dyn., 42(7-8), 1999-2018, doi:10.1007/s00382-013-1783-z.

Bonham, S. G., A. M. Haywood, D. J. Lunt, M. Collins, and U. Salzmann (2009), El Nino-Southern Oscillation, Pliocene climate and equifinality, Philos. Trans. R. Soc. A, 367(1886), 127-156, doi:10.1098/rsta.2008.0212.

Bragg, F. J., D. J. Lunt, and A. M. Haywood (2012), Mid-Pliocene climate modelled using the UK Hadley Centre Model: PlioMIP Experiments 1 and 2, Geosci. Model Dev., 5(5), 1109-1125, doi:10.5194/gmd-5-1109-2012.

Brierley, C. M. (2015), Interannual climate variability seen in the Pliocene Model Intercomparison Project, Clim. Past, 11(3), $605-618$.

Cai, W., P. van Rensch, T. Cowan, and H. H. Hendon (2011), Teleconnection pathways of ENSO and the IOD and the mechanisms for impacts on Australian rainfall, J. Clim., 24(15), 3910-3923, doi:10.1175/2011JCLI4129.1.

Cai, W., et al. (2014), Increasing frequency of extreme El Niño events due to greenhouse warming, Nat. Clim. Change, 4(2), 111-116, doi:10.1038/NCLIMATE2100.

Cane, M., G. Eshel, and R. Buckland (1994), Forecasting Zimbabwean maize yield using eastern equatorial Pacific sea-surface temperature, Nature, 370(6486), 204-205, doi:10.1038/370204a0

Capotondi, A., et al. (2015), Understanding ENSO diversity, Bull. Am. Meteorol. Soc., 96(6), 921-938, doi:10.1175/BAMS-D-13-00117.1.

Chan, J., and W. Zhou (2005), PDO, ENSO and the early summer monsoon rainfall over south China, Geophys. Res. Lett., 32, L08810, doi:10.1029/2004GL022015.

Changnon, S. A. (Ed.) (2000), El Niño 1997-1998: The Climate Event of the Century, Oxford Univ. Press, New York.

Cobb, K. M., N. Westphal, H. R. Sayani, J. T. Watson, E. Di Lorenzo, H. Cheng, R. L. Edwards, and C. D. Charles (2013), Highly variable El Niño-Southern Oscillation throughout the Holocene, Science, 339(6115), 67-70, doi:10.1126/science.1228246. 
Collins, M., et al. (2010), The impact of global warming on the tropical Pacific Ocean and El Niño, Nat. Geosci., 3(6), 391-397, doi:10.1038/NGEO868.

Cox, P. (2001), Description of the TRIFFID dynamic global vegetation model, Tech. Rep. 24, UKMO, Hadley Centre. [Available at https://library.metoffice.gov.uk/M10326UK/OPAC/Search/AdvancedSearch.aspx Accessed: 29th September 2016.]

Cox, P., R. A. Betts, C. B. Bunton, R. L. H. Essery, P. R. Rowntree, and J. Smith (1999), The impact of new land surface physics on the GCM simulation of climate and climate sensitivity, Clim. Dyn., 15(3), 183-203.

Dolan, A. M., A. M. Haywood, D. J. Hill, H. J. Dowsett, S. J. Hunter, D. J. Lunt, and S. J. Pickering (2011), Sensitivity of Pliocene ice sheets to orbital forcing, Palaeogeogr. Palaeoclimatol. Palaeoecol., 309(1-2), 98-110.

Dowsett, H., R. Thompson, J. Barron, T. Cronin, F. Fleming, S. Ishman, R. Poore, D. Willard, and T. Holtz (1994), Joint investigations of the middle pliocene climate: 1. PRISM paleoenvironmental reconstructions, Glob. Planet. Chang., 9(3-4), 169-195.

Dowsett, H., M. Robinson, A. Haywood, U. Salzmann, D. Hill, L. Sohl, M. Chandler, M. Williams, K. Foley, and D. Stoll (2010), The PRISM3D paleoenvironmental reconstruction, Stratigraphy, 7(2-3), 123-139.

Edwards, J. M., and A. Slingo (1996), Studies with a flexible new radiation code: 1 . Choosing a configuration for a large-scale model, Q. J. R. Meteorol. Soc., 122(531), 689-719.

Essery, R., M. Best, and P. Cox (2001), MOSES2.2 technical documentation, Tech. Rep. 30, UKMO, Hadley Centre. [Available at https://library.metoffice.gov.uk/M10326UK/OPAC/Search/AdvancedSearch.aspx Accessed: 29th September 2016.]

Glynn, P., and W. Deweerdt (1991), Elimination of 2 Reef-Building Hydrocorals following the 1982-83 El-Niño warming event, Science, 253(5015), 69-71, doi:10.1126/science.253.5015.69.

Gordon, C., C. Cooper, C. Senior, H. Banks, J. Gregory, T. Johns, J. Mitchell, and R. Wood (2000), The simulation of SST, sea ice extents and ocean heat transports in a version of the Hadley Centre coupled model without flux adjustments, Clim. Dyn., 16(2-3), 147-168.

Gregory, D., and D. Morris (1996), The sensitivity of climate simulations to the specification of mixed phase clouds, Clim. Dyn., 12(9), $641-651$.

Gregory, D., and P. R. Rowntree (1990), A mass flux convection scheme with representation of cloud ensemble characteristics and stability-dependent closure, Mon. Weather Rev., 118(7), 1483-1506.

Guilyardi, E., P. Braconnot, F.-F. Jin, S. T. Kim, M. Kolasinski, T. Li, and I. Musat (2009), Atmosphere feedbacks during ENSO in a coupled GCM with a modified atmospheric convection scheme, J. Clim., 22(21), 5698-5718, doi:10.1175/2009JCLI2815.1.

Haywood, A. M., P. J. Valdes, and B. W. Sellwood (2000), Global scale palaeoclimate reconstruction of the middle Pliocene climate using the UKMO GCM: Initial results, Glob. Planet. Chang., 25(3-4), 239-256.

Haywood, A. M., H. J. Dowsett, M. M. Robinson, D. K. Stoll, A. M. Dolan, D. J. Lunt, B. Otto-Bliesner, and M. A. Chandler (2011), Pliocene Model Intercomparison Project (PlioMIP): Experimental design and boundary conditions (Experiment 2), Geosci. Model Dev., 4(3), 571 -577.

Haywood, A. M., et al. (2013), Large-scale features of Pliocene climate: Results from the Pliocene Model Intercomparison Project, Clim. Past, $9(1), 191-209$.

Haywood, A. M., P. J. Valdes, and V. L. Peck (2007), A permanent El Niño-like state during the Pliocene?, Paleoceanography, 22, doi:10.1029/2006PA001323.

Haywood, A. M., et al. (2013), On the identification of a Pliocene time slice for data-model comparison, Philos. T. Roy. Soc. A, 371, 20120515, doi:10.1098/rsta.2012.0515.

Hoerling, M., A. Kumar, and M. Zhong (1997), El Niño, La Niña, and the nonlinearity of their teleconnections, J. Clim., 10(8), 1769-1786, doi:10.1175/1520-0442(1997)010<1769:ENOLNA>2.0.CO;2.

Johnson, N. C. (2013), How many ENSO flavors can we distinguish?, J. Clim., 26(13), 4816-4827, doi:10.1175/JCLI-D-12-00649.1.

Kao, H.-Y., and J.-Y. Yu (2009), Contrasting eastern-Pacific and central-Pacific types of ENSO, J. Clim., 22(3), 615-632, doi:10.1175/2008JCLI2309.1.

Karnauskas, K. B. (2013), Can we distinguish canonical El Nino from Modoki?, Geophys. Res. Lett., 40(19), 5246-5251, doi:10.1002/grl.51007.

Krapp, M., and J.-H. Jungclaus (2015), Pacific variability under present-day and Middle Miocene boundary conditions, Clim. Dyn., 44(9-10), 2609-2621, doi:10.1007/s00382-014-2456-2.

Kug, J.-S., F.-F. Jin, and S.-I. An (2009), Two types of El Nino events: Cold tongue El Niño and warm pool El Niño, J. Clim., 22(6), 1499-1515, doi:10.1175/2008JCLI2624.1.

Larkin, N., and D. Harrison (2005), On the definition of El Niño and associated seasonal average U.S. weather anomalies, Geophys. Res. Lett., 32, L13705, doi:10.1029/2005GL022738.

L'Heureux, M., and D. Thompson (2006), Observed relationships between the El Niño-Southern Oscillation and the extratropical zonal-mean circulation, J. Clim., 19(2), 276-287, doi:10.1175/JCLI3617.1.

Li, J., S.-P. Xie, E. R. Cook, G. Huang, R. D'Arrigo, F. Liu, J. Ma, and X.-T. Zheng (2011), Interdecadal modulation of El Niño amplitude during the past millennium, Nat. Clim. Change, 1(2), 114-118, doi:10.1038/NCLIMATE1086.

Li, J., S.-P. Xie, E. R. Cook, M. S. Morales, D. A. Christie, N. C. Johnson, F. Chen, R. D’Arrigo, A. M. Fowler, X. Gou, and K. Fang (2013), El Niño modulations over the past seven centuries, Nat. Clim. Change, 3(9), 822-826, doi:10.1038/NCLIMATE1936.

Lunt, D. J., A. M. Haywood, G. A. Schmidt, U. Salzmann, P. J. Valdes, H. J. Dowsett, and C. A. Loptson (2012), On the causes of mid-Pliocene warmth and polar amplification, Earth Planet. Sci. Lett., 321, 128-138, doi:10.1016/j.epsl.2011.12.042.

Mantua, N., and S. Hare (2002), The Pacific Decadal Oscillation, J. Oceanogr., 58(1), 35-44, doi:10.1023/A:1015820616384.

McGregor, S., A. Timmermann, M. H. England, O. E. Timm, and A. T. Wittenberg (2013), Inferred changes in El Niño-Southern Oscillation variance over the past six centuries, Clim. Past, 9(5), 2269-2284, doi:10.5194/cp-9-2269-2013.

McPhaden, M. J., S. E. Zebiak, and M. H. Glantz (2006), ENSO as an integrating concept in Earth science, Science, 314(5806), 1740-1745, doi:10.1126/science.1132588.

Meehl, G. (1996), Vulnerability of freshwater resources to climate change in the tropical Pacific region, Water Air Soil Pollut., 92(1-2), 203-213, Regional Workshop on Climate Change Vulnerability and Adaptation in Asia and the Pacific, Manila, Philippines, Jan. 15-19, 1996.

Molnar, P., and M. Cane (2002), El Niño's tropical climate and teleconnections as a blueprint for pre-lce Age climates, Paleoceanography, 17(2), 1021, doi:10.1029/2001PA000663.

Newman, M., G. Compo, and M. Alexander (2003), ENSO-forced variability of the Pacific decadal oscillation, J. Clim., 16(23), 3853-3857, doi:10.1175/1520-0442(2003)016<3853:EVOTPD>2.0.CO;2.

Oshima, K., and Y. Tanimoto (2009), An evaluation of reproducibility of the Pacific Decadal Oscillation in the CMIP3 simulations, J. Meteorol. Soc. Jpn., 87(4), 755-770, doi:10.2151/jmsj.87.755.

Philander, S. (1983), Meteorology_Anomalous El-Niño of 1982-83, Nature, 305(5929), 16, doi:10.1038/305016a0.

Philander, S., and A. Fedorov (2003), Role of tropics in changing the response to Milankovich forcing some three million years ago, Paleoceanography, 18(2), 1045, doi:10.1029/2002PA000837. 
Pope, V., M. Gallani, P. Rowntree, and R. Stratton (2000), The impact of new physical parametrizations in the Hadley Centre climate model: HadAM3, Clim. Dyn., 16(2-3), 123-146.

Power, S., M. Haylock, R. Colman, and X. Wang (2006), The predictability of interdecadal changes in ENSO activity and ENSO teleconnections, J. Clim., 19(19), 4755-4771, doi:10.1175/JCLI3868.1.

Power, S., F. Delage, C. Chung, G. Kociuba, and K. Keay (2013), Robust twenty-first-century projections of El Niño and related precipitation variability, Nature, 502(7472), 541-545, doi:10.1038/nature12580.

Prescott, C. L., A. M. Haywood, A. M. Dolan, S. J. Hunter, J. O. Pope, and S. J. Pickering (2014), Assessing orbitally-forced interglacial climate variability during the mid-Pliocene Warm Period, Earth. Planet. Sci. Lett., 400, 261-271.

Salzmann, U., A. M. Haywood, D. J. Lunt, P. J. Valdes, and D. J. Hill (2008), A new global biome reconstruction and data-model comparison for the Middle Pliocene, Global Ecol. Biogeogr., 17(3), 432-447.

Salzmann, U., et al. (2013), Challenges in quantifying Pliocene terrestrial warming revealed by data-model discord, Nat. Clim. Change, 3(11), 969-974.

Schneider, N., and B. Cornuelle (2005), The forcing of the Pacific decadal oscillation, J. Clim., 18(21), 4355-4373, doi:10.1175/JCLI3527.1.

Scroxton, N., S. Bonham, R. E. M. Rickaby, S. H. F. Lawrence, M. Hermoso, and A. M. Haywood (2011), Persistent El Niño-Southern Oscillation variation during the Pliocene Epoch, Paleoceanography, 26, PA2215, doi:10.1029/2010PA002097.

Seki, O., G. L. Foster, D. N. Schmidt, A. Mackensen, K. Kawamura, and R. D. Pancost (2010), Alkenone and boron-based Pliocene $p C_{2}$ records, Earth Planet. Sci. Lett., 292(1-2), 201-211, doi:10.1016/j.epsl.2010.01.037.

Seki, O., D. N. Schmidt, S. Schouten, E. C. Hopmans, J. S. S. Damste, and R. D. Pancost (2012), Paleoceanographic changes in the Eastern Equatorial Pacific over the last 10 Myr, Paleoceanography, 27, PA3224, doi:10.1029/2011PA002158.

Semtner, A. J. (1976), Model for thermodynamic growth of sea ice in numerical investigations of climate, J. Phys. Oceanogr., 6(3), 379-389.

Smith, R. N. B. (1990), A scheme for predicting layer clouds and their water-content in a general-circulation model, Q. J. R. Meteorol. Soc., $116(492), 435-460$.

Solomon, S., D. Qin, M. Manning, a. M. M. Z. Chen, K. B. Averyt, M. Tignor, and H. L. Miller (Eds.) (2007), IPCC, 2007 Climate Change 2007: The Physical Science Basis. Contribution of Working Group I to the Fourth Assessment Report of the Intergovernmental Panel on Climate Change, Cambridge Univ. Press, Cambridge, U. K., and New York.

Stocker, T. F., D. Qin, G. K. Plattner, M. Tignor, S. K. Allen, J. Boschung, A. Nauels, Y. Xia, V. Bex, and P. M. Midgley (Eds.) (2013), IPCC, 2013 Climate Change 2013: The Physical Science Basis. Contribution of Working Group I to the Fifth Assessment Report of the Intergovernmental Panel on Climate Change, Cambridge Univ. Press, Cambridge, U. K., and New York.

The Economist (1998), The season of El Niño, The Economist Newspaper Limited, London. [Available at http://www.economist.com/node/ 127009. Accessed 29th September 2016.]

Verdon, D., and S. Franks (2006), Long-term behaviour of ENSO: Interactions with the PDO over the past 400 years inferred from paleoclimate records, Geophys. Res. Lett., 33, L06712, doi:10.1029/2005GL025052.

von der Heydt, A. S., A. Nnafie, and H. A. Dijkstra (2011), Cold tongue/warm pool and ENSO dynamics in the Pliocene, Clim. Past, 7(3), 903-915, doi:10.5194/cp-7-903-2011.

Wara, M., A. Ravelo, and M. Delaney (2005), Permanent El Niño-like conditions during the Pliocene warm period, Science, 309(5735), 758-761, doi:10.1126/science.1112596.

Watanabe, T., et al. (2011), Permanent El Niño during the Pliocene warm period not supported by coral evidence, Nature, 471(7337), $209-211$.

Winnick, M. J., J. M. Welker, and C. P. Chamberlain (2013), Stable isotopic evidence of El Niño-like atmospheric circulation in the Pliocene western United States, Clim. Past, 9(5), 2085-2099.

Wittenberg, A. T. (2009), Are historical records sufficient to constrain ENSO simulations?, Geophys. Res. Lett., 36, L12702, doi:10.1029/2009GL038710.

Yeh, S.-W., J.-S. Kug, B. Dewitte, M.-H. Kwon, B. P. Kirtman, and F.-F. Jin (2009), El Niño in a changing climate, NATURE, 461(7263), 511-514, doi:10.1038/nature08316.

Zhang, Y., J. Wallace, and D. Battisti (1997), ENSO-like interdecadal variability: 1900-93, J. Clim., 10(5), 1004-1020 doi:10.1175/1520-0442(1997)010<1004:ELIV>2.0.CO;2

Zhang, Y. G., M. Pagani, and Z. Liu (2014), A 12-million-year temperature history of the tropical Pacific Ocean, Science, 344(6179), 84-87, doi:10.1126/science.1246172.

Zhang, Z., Q. Yan, J. Z. Su, and Y. Q. Gao (2012), Has the problem of a permanent El Niño been resolved for the Mid-Pliocene?, Atmos. Oceanic Sci. Lett., 5(6), 445-448, doi:10.1080/16742834.2012.11447035. 